\title{
Wormlike Micellar Solutions, Beyond the Chemical Enhanced Oil Recovery Restrictions
}

\author{
Emad Jafari Nodoushan ${ }^{1}$, Taeil Yi ${ }^{2}$, Young Ju Lee ${ }^{1,3}$ and Namwon Kim ${ }^{1,4, *}$ \\ 1 Materials Science, Engineering, and Commercialization, Texas State University, San Marcos, TX 78666, USA; \\ e_j107@txstate.edu (E.J.N.); y_139@txstate.edu (Y.J.L.) \\ 2 School of Mechanical Engineering, Kyungnam University, Changwon 51767, Korea; \\ yti0811@kyungnam.ac.kr \\ 3 Department of Mathematics, Texas State University, San Marcos, TX 78666, USA \\ 4 Ingram School of Engineering, Texas State University, San Marcos, TX 78666, USA \\ * Correspondence: n_k43@txstate.edu
}

Received: 10 June 2019; Accepted: 10 September 2019; Published: 17 September 2019

check for updates

\begin{abstract}
While traditional oil recovery methods are limited in terms of meeting the overall oil demands, enhanced oil recovery (EOR) techniques are being continually developed to provide a principal portion of our energy demands. Chemical EOR (cEOR) is one of the EOR techniques that shows an efficient oil recovery factor in a number of oilfields with low salinity and temperature ranges. However, the application of $c E O R$ under the harsh conditions of reservoirs where most of today's crude oils come from remains a challenge. High temperatures, the presence of ions, divalent ions, and heterogeneous rock structures in such reservoirs restrict the application of cEOR. Polymer solutions, surfactants, alkaline-based solutions, and complex multi-components of them are common chemical displacing fluids that failed to show successful recovery results in hostile conditions for various reasons. Wormlike micellar solutions (WMS) are viscoelastic surfactants that possess advantageous characteristics for overcoming current cEOR challenges. In this study, we first review the major approaches and challenges of commonly used chemical agents for cEOR applications. Subsequently, we review special characteristics of WMS that make them promising materials for the future of $c E O R$.
\end{abstract}

Keywords: wormlike micellar solutions (WMS); enhanced oil recovery (EOR); chemical EOR (cEOR); viscoelastic surfactants (VES)

\section{Introduction}

In primary oil extraction methods, the natural pressure of the reservoir and artificial lift oil devices are in use for oil extraction, which results in an average recovery factor of less than $30 \%$ of oils in a reservoir [1]. Secondary oil recovery methods, such as water or gas injection, are then applied to force the oil resting in the reservoir and push them to the surface of the earth. However, more than $50 \%$ of oil in a reservoir remains trapped. Tertiary or enhanced oil recovery (EOR) methods are techniques seeking to increase reservoir pressure or alter immobile oils properties to make trapped oils more conducive for extraction [1,2]. A general classification of EOR methods had been provided by Thomas, as represented in Figure 1 [3]. Capillary Number $\left(\mathrm{N}_{\mathrm{c}}\right)$ and mobility ratio $(\mathrm{M})$ are two major parameters that determine the mobilization of the residual oil in the reservoirs. $\mathrm{N}_{\mathrm{c}}$ and $\mathrm{M}$ are defined, as the following:

$$
\begin{aligned}
& \mathrm{N}_{\mathrm{c}}=\frac{\mathrm{v \eta}}{\sigma} \\
& \mathrm{M}=\frac{\lambda \mathrm{ing}}{\lambda \mathrm{ed}}
\end{aligned}
$$


where $\mathrm{v}$ is the Darcy velocity $(\mathrm{m} / \mathrm{s}), \eta$ is the dynamic viscosity of a displacing fluid (Pa.s), $\sigma$ is the interfacial tension ( $\mathrm{N} / \mathrm{m}), \lambda_{\text {ing }}$ is the mobility of the displacing fluid (e.g., water), and $\lambda_{\text {ed }}$ is the mobility of the displaced fluid (e.g., oil). The mobility factor of each fluid is defined as:

$$
\lambda=\frac{\mathrm{k}}{\eta}
$$

where $\mathrm{k}$ is the effective permeability $\left(\mathrm{m}^{2}\right)[3,4]$. In chemical EOR methods (cEOR), a chemical formulation is added to displacing fluid with the aim of decreasing the mobility ratio and/or enhancing the capillary number. Two major approaches in cEOR are (1) increasing the viscosity of the displacing fluid, which results in an enhancement in the mobility and improving the volumetric sweep efficiency and (2) adding chemicals to decrease the interfacial tension (IFT, $\sigma$ in Equation (1)) between the oil and displacement fluid that allows trapped oil to flow through low-permeability zones [5].

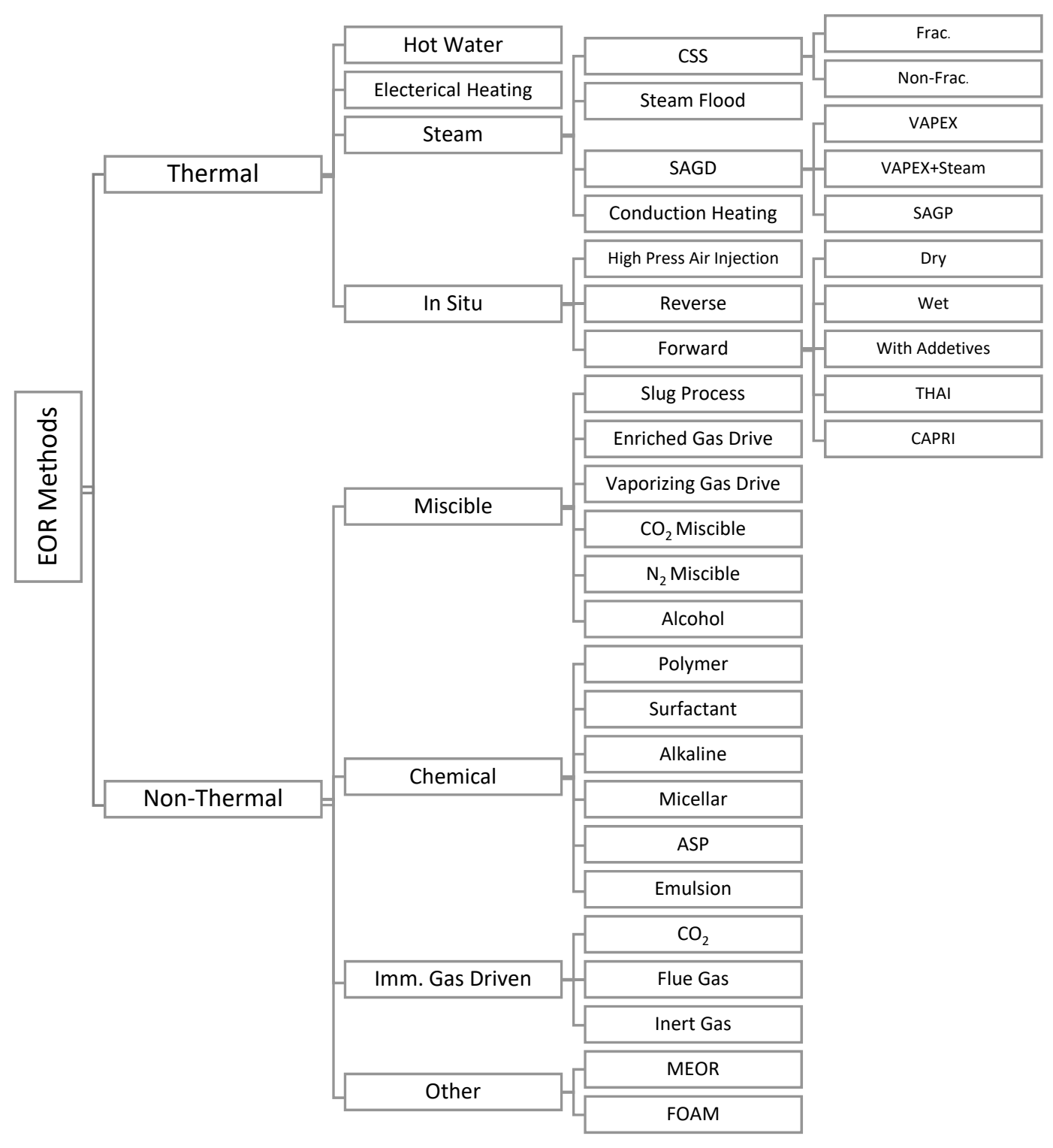

Figure 1. Classification of enhanced oil recovery (EOR) methods. Reproduced from reference [3] under a Creative Commons license.

Water-based polymer solutions, surfactants, low-salinity water, and alkalizes were reported as useful displacing fluids for cEOR [6-9]. Commercial EOR chemicals were applied for years in reservoirs 
with low temperatures and low-salinity brines [10]. However, these chemical agents generally suffer from poor salt and temperature tolerances, in addition to problems, such as loss of viscosity due to shear degradation when injecting them into reservoirs under harsh conditions [10,11]. The challenge lies in developing EOR chemicals for high-temperature and high-salinity reservoirs [12,13]. In next sections, we survey the most important polymeric and surfactant-based chemical agents for cEOR and address their major problems restricting efficient EOR. Afterwards, we review the wormlike micellar solutions (WMS) and their characteristics that make them promising candidates for the future of cEOR applications.

\section{Non-Newtonian Displacing Fluids}

Displacing fluids, such as polymer solutions and viscoelastic surfactant solutions, are Non-Newtonian fluids [14-17]. These fluids do not follow the Newtonian law of viscosity $(\tau=\eta \dot{\gamma})$, where viscosity $(\eta)$ is independent of the applied shear rate $(\dot{\gamma})$. Instead, the majority of displacing fluids show shear-thinning behavior that shows decreased viscosity $(\eta(\dot{\gamma}) \neq$ Constant) with higher shear rates [18]. Shear-thinning behavior is of importance in cEOR, because it facilitates the injectivity of displacing fluids by decreasing the viscosity of fluid under high stresses presented in oil reservoirs [19]. However, the shear-thinning characteristic of the fluid is unfavorable for sweeping oil, because the loss of viscosity would lower the mobility ratio (see Equations (2) and (3)). In addition, shear-thinning displacing fluids tend to flow through high permeability zones of oil reservoir, while low permeability zones remain un-swept $[20,21]$. Therefore, displacing fluids showing shear-thickening characteristics attracted interest $[15,22,23]$. Shear-thickening, an enhancement of fluid viscosity when fluid is subjected to incremental stresses, is observed in wormlike micellar solutions (WMS) when the solutions are sheared beyond a critical shear rate [24,25]. The shear-thickening characteristic is attributed to the formation of shear-induced structures (SIS) (see Section 6.3 for more details) and it is advantageous for retarding the flow of displacing fluids that are injected in high-permeability zones of oil reservoirs $[20,26]$. A further discussion on the characteristics of displacing fluids caused by their non-Newtonian rheology is presented in Sections 6.1-6.3.

\section{Polymeric Solutions Restrictions as cEOR Agents}

Various polymers, such as hydrolyzed polyacrylamide (HPAM) [27], xanthan gum [28], salinity-tolerant polymer KYPAM [29], hydrophobically associating polymers, and 2-acrylamide-2-methyl propane-sulfonate co-polymers (AMPS) [30], have been examined for applications in cEOR. Even though HPAM or xanthan gum are used as one of main components for polymer displacing fluids, xanthan gum is different from HPAM, as it is a biopolymer. Since biocides are required to avoid the biological degeneration of the biopolymers, the process is quite expensive and economically unfeasible. When considering this, HPAM is the most widely used polymer for mobility control [7,31]. The backbone of HPAM consists of monomer units of acrylamide and acrylic acids. In aqueous solutions with low salinity, such as deionized water, the charge repulsion of the carboxylic groups on the HPAM backbone elongates the chain structure, which results in a highly viscous HPAM solution. However, the carboxylic group's charges are neutralized or shielded by salt ions of high-salinity brine solutions and, in turn, the HPAM chains lose their stretched states and the viscosity of solution decreases [31].

The temperature of the reservoir is also another critical factor that affects HPAM hydrolysis in cEOR applications [32-34]. The reservoirs, which are dormant candidates for cEOR methods, in certain areas, such as in Kuwait, Malaysia, Canada, Germany, etc., have issues that are related to this [34-36]. The salinity of reservoir brine is usually more than $200,000 \mathrm{ppm}$ and the temperatures vary from $70{ }^{\circ} \mathrm{C}$ to $120^{\circ} \mathrm{C}$ in those regions $[7,35,37]$. However, the working temperature of HPAM polymers is below $60^{\circ} \mathrm{C}$ and the salinity resistance of them is below 35,000 ppm of $\mathrm{NaCl}$, including $1000 \mathrm{ppm}$ of divalent salts. Copolymers of acrylamide and sodium salt of acrylamide propyl sulfonated (AMPS) acid were introduced to overcome those shortcomings, which are more tolerant against the salts and 
high temperature when compared to HPAM polymers. Nevertheless, the AMPS polymers have lower viscosities than HPAMs due to the low solubility of AMPS in water [35,37-39]. Low-permeability layers in a reservoir will be blocked after improper employment of AMPS fluids due to the presence of the bulky polymer chains and surfactant foams. This event will cause a drop in the amount of oil production from these regions. Another problem that is associated with polymer solutions is the rise in the effect of preferential flow in high-permeability zones because of the decreased viscosity that is caused by the shear-thinning nature of the polymers [12,40,41].

In many well site treatments, the operational complexity of fluid delivery significantly influences the total treatment cost, speed, and reliability. Traditional oilfield fluid thickeners consist of high-molecular-weight biopolymers, such as guar and derivatized cellulose and, sometimes, synthetic polymers such as polyacrylamides [42]. Although these polymers have effective viscosities, they often require specific mixing and hydration procedures, as well as many field-specific chemical additives. If a polymer solution is to be crosslinked for enhanced viscosity, additional crosslinking agents, such as borate or zirconium ions, must be introduced along with appropriate $\mathrm{pH}$ buffers. If a crosslinked polymer solution cannot be reliably delivered through a tube due to shear degradation or excessive frictional pressure, then additional treatments that allow for temporal suspension of the crosslinking must be consolidated into the fluid design [42,43]. The treatments that can be considered include using competing ligands to temporarily bind the metal crosslinking agents, adding $\mathrm{pH}$ buffers to control the crosslinking reaction kinetics, or using two or more organometallic complexes as crosslinking agents, in which one can limit the crosslinking for initial transportation in the tube and another can initiate the crosslinking in the fracture site. However, organometallic crosslinked fluids require complex formulations that have to be modulated for each treatment operation [43]. Various oil field conditions, including mix-water composition, tubular shear rate, well depth, and temperature, require corresponding performance-adjusting additives and make it difficult to routinely achieve maximum efficiency [8]. While considering the discussion, it is important to review alternative materials that are technically applicable for cEOR.

\section{Surfactant-Based Fluids}

Surfactants are added to displacing fluid to decrease IFT between oil and injected recovery fluid to enhance trapped oil recovery through tight pore necks and low-permeability zones of reservoirs $[3,35,44]$. However, these solutions are not capable of withstanding the harsh conditions of reservoirs. The mineral components of rock formations play a key role in reaction with and absorption of surfactants. Moreover, cleaning the surfactants emulsions and disposal treatment of them remain a challenge $[44,45]$. Materials containing alkaline components can react with the acid portion of the crude oil. The reaction results in the production of surfactants in situ. The major purpose of using alkaline chemicals is to reduce the IFT, because it can cause wettability alterations $[9,46,47]$. The complexity of the process design because of the various undesired reactions in the reservoirs that can occur and the low recovery factor of $0-3 \%$ of oil in place (OIP) are discouragements of using these chemical agents [46].

Alkaline-surfactant-polymer displacing fluids have been evaluated through laboratory experiments and reported during recent decades [48]. However, multi-component displacing fluids are exposed to chromatographic separation in the oil reservoirs. This was demonstrated to occur in the Daqing reservoirs in China [49,50].

\section{Viscoelastic Surfactants}

Viscoelastic surfactants (VES) were initially introduced by Dow Chemicals as wormlike micelles and were used as thickeners in consumer products [51]. VES are also promising chemical agents for cEOR that provide a combination of viscosifying agents (i.e., water-based polymer solutions) and a lowering of IFT chemicals (i.e., surfactants), which results in advantages in the recovery of oil. Surfactants that are added to displacing fluids form spherical micelles of oil in water, while VES are 
self-assemblies with longer and complex structures that maintain a high viscosity in displacing fluid, even at a low concentration [52-54]. At the same time, their surface-active molecules decrease the IFT [21,52]. Morvan et al. investigated the effect of the addition of wormlike micelles to displacing fluids. In core flood experiments with low-salinity brine, WMS injection resulted in a significantly higher recovery of oil than with a water injection alone [54]. There is a complex interplay of properties and characteristics that make VES/WMS powerful candidates for cEOR. In the next sections, WMS and unique characteristics of wormlike micelles are reviewed in more detail.

\section{Wormlike Micellar Solutions (WMS)}

WMS have emerged as a suitable alternative material to polymer solutions for cEOR. The surfactants begin to form micelles through self-assembly above the critical micelle concentration (CMC) $[12,55]$. Amongst the several types of supramolecular micelles, the very long cylindrical and flexible wormlike micelles have attained considerable interest from both theorists and experimentalists in virtue of their unique micellar constructions and remarkable rheological responses. The rheological characteristics of these WMS are comparable to polymer solutions [56]. The ability of wormlike micelles in increasing the viscosity of water-based solutions (water thickening) are identified as being similar to that of water-soluble polymers. Although the long cylindrical chains of wormlike micelles show similarity to the long chain of high-molecular-weight polymers, the rheological behavior of WMS is more complex than that of polymer solutions. Typically, WMS systems are formed from a mixture of surfactants and salts, and any change in the concentration of each component can contribute to a change in the rheological behavior of WMS. Moreover, the solubility of surfactant and salts in aqueous solvents is a function of temperature [57]. The driving force in the formation of micellar aggregations is hydrophobic interactions, which are physical interactions that are weaker than the covalent bonds that form the polymers' backbone structures. Thus, unlike polymer chains that are difficult to break once they are formed, micellar structures break and reform continuously. The kinetics of formation and scission of wormlike micellar structures is also a function of temperature [58]. Therefore, WMS are highly sensitive to temperature, because any change in temperature results in altering the solubility of micellar components in the solution and, also, the change in kinetics of micellar reversible scission. In this way, WMS chains are more sensitive to conditions, such as temperature. Wang et al. [59] reported the rheological comparison between the WMS and ultrahigh molecular weight (UHMW) polymer aqueous solution. They chose erucyl dimethyl amidoprpyl betaine (EDAB) to form long WMS chains that are independent of salt and nonionic polyacrylamide (PAM) for a 12 MDa UHMW polymer solution, which demonstrated a strong thickening capability in saline water at room temperature. It has been reported that both WMS and UHMW polymer solution are effective water thickeners and are able to retain considerable viscosity up to $85^{\circ} \mathrm{C}$. However, the dynamic viscosity of WMS follows the Maxwellian model with a single relaxation time, while the UHMW PAM solution demonstrates a spectrum of relaxation times. Figure 2 shows the zero-shear viscosity $\left(\eta_{0}\right)$ of both WMS and UHMW PAM in an Arrhenius plot. While both show an exponential decrease in their zero-shear viscosity at higher temperatures, the higher slope of WMS confirms that they are more sensitive to temperature than the UHMW polymer solution [59]. 


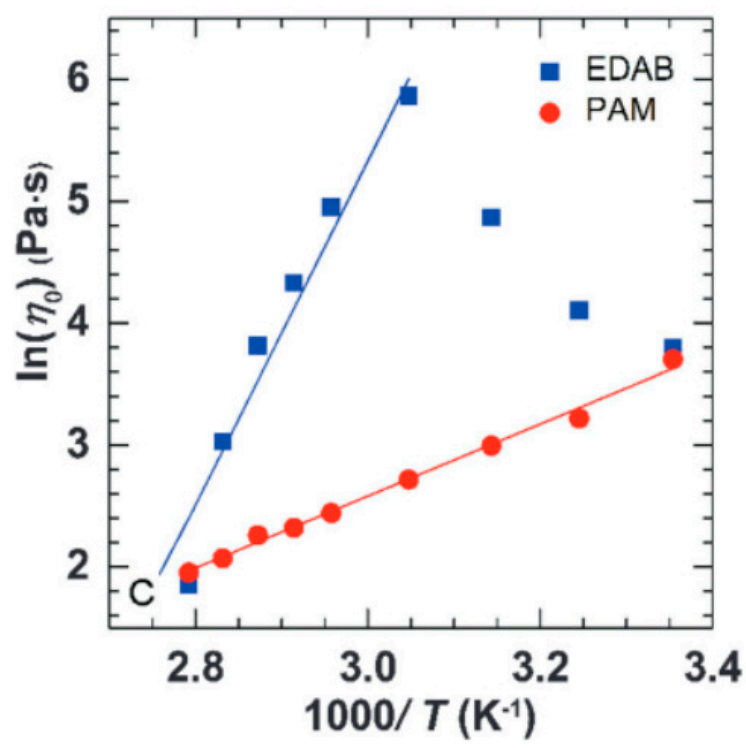

Figure 2. Arrhenius plot of zero-shear viscosity of erucyl dimethyl amidoprpyl betaine (EDAB) and ultrahigh molecular weight (UHMW) polyacrylamide (PAM) verses 1/T. Reprinted from reference [59] with permission from the Royal Society of Chemistry.

\subsection{Shear-Thickening Behavior}

Several methods have been developed to induce wormlike micelles from spherical micelles. One way is to increase the concentration of a surfactant with extra counter ions, which leads to the growth of the micelles in one dimension, resulting in the wormlike configuration. The nature of viscosity depends on both the size and shape of the solutes in a solution at the same concentration. Even for similarly sized solutes, a solution with solutes of a relatively higher aspect ratio, such as wormlike micelles, has a higher viscosity than a solution with lower aspect ratio solutes. As aforementioned, WMS behave in a similar way as many polymer solutions in terms of mechanical disturbance and viscoelasticity [60]. The majority of viscoelastic fluids that are being used for cEOR show shear-thinning behavior [14,15]. However, Liu and Pine reported unusual behavior in viscosity of WMS that they prepared while using aqueous solutions of hexadecyltrimethyl ammonium bromide (CTAB) and sodium salicylate (NaSal) [61]. Figure 3 shows the viscosities of WMS as a function of shear rate for three different concentrations of $\mathrm{CTAB} / \mathrm{NaSal}$ in water. When the solutions are sheared beyond a critical shear rate, they show a sudden increase in viscosity, so-called shear-thickening behavior [62-64].

The power-law model given by Equation (4) is a simple mathematical model that describes the behavior of fluids:

$$
\eta(\dot{\gamma})=K \dot{r}^{n-1}
$$

where $\mathrm{K}$ is the flow consistency index and $\mathrm{n}$ is the flow behavior index. Based on the value of $\mathrm{n}$, the fluid behavior is either shear-thinning $(n<1)$, Newtonian $(n=1)$, or shear-thickening $(n>1)$ [65]. However, viscosity curve of a shear-thickening fluid is typically constituted of three regions: a slight shear-thinning at low shear rates, a subsequent viscosity increases over a critical shear rate, and a shear-thinning region at high shear rates [66]. Therefore, a power law model fails to describe the fluid behavior in the entire range of applied shear rates. For example, while a power-law model (with $n>1$ ) can describe the shear-thickening behavior of fluid in intermediate shear rates, it fails to fit the regions of low and high shear rates where the fluid shows the shear-thinning (Figure 3b). Galindo-Rosales et 
al. [67] suggested a composite function that is given by Equation (5), taking all regions of viscosity curve into account:

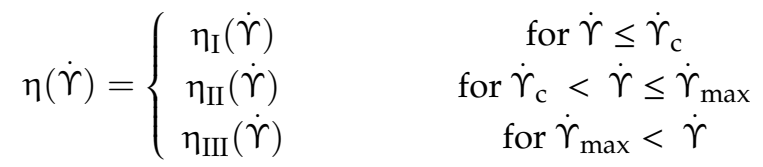
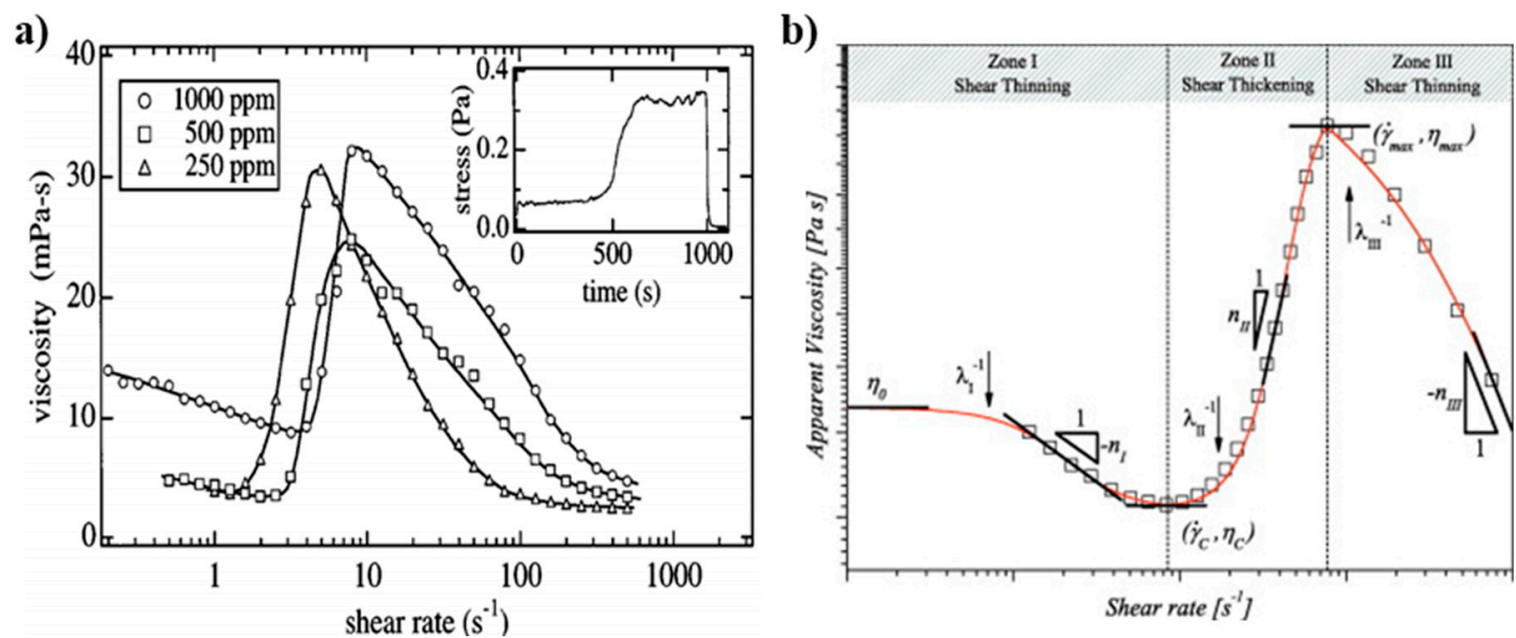

Figure 3. (a) Variation in the viscosity as a function of shear rate for hexadecyltrimethyl ammonium bromide/sodium salicylate wormlike micellar solutions (CTAB/NaSal WMS). The inset illustrates the shear stress over time after applying a constant shear rate. The stress increases after an induction period of 400-500 s and relaxes in a few seconds upon cessation of shear flow. Reprinted from reference [61] with permission from the American Physical Society. (b) Three typical zones of I: shear-thinning, II: shear-thickening, and III: shear-thinning in a log-log viscosity plot of a shear-thickening fluid. Reprinted from reference [66] with permission from Elsevier.

In this equation, $\dot{\Upsilon}_{\mathrm{c}}$ is the critical shear rate and $\dot{\Upsilon}_{\max }$ is the shear rate in which fluid show the highest viscosity. The viscosity functions of $\eta_{i}$ (for $i=$ I, II, III) are branched equations based on the Cross model [68]:

$$
\eta=\eta_{\infty}+\frac{\eta_{0}-\eta_{\infty}}{1+(\lambda \dot{r})^{n}}
$$

where $\eta_{\infty}$ is the infinite shear viscosity, $\eta_{0}$ is the zero-shear viscosity, and $\lambda$ is the relaxation time of the fluid. The final form of suggested model is as follows:

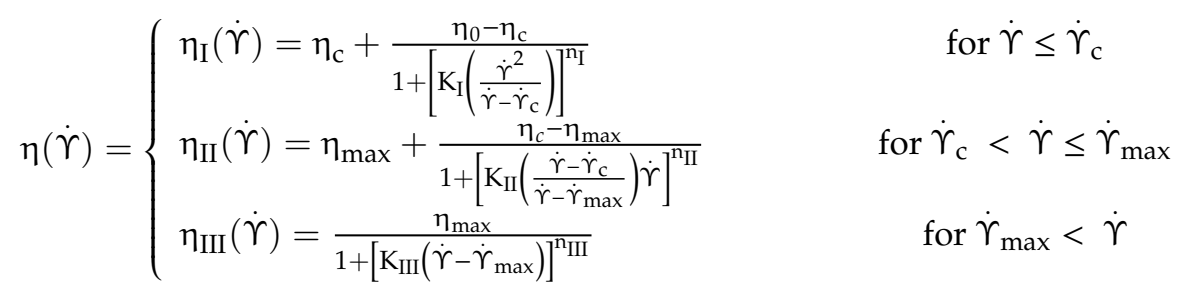

where $\mathrm{K}_{\mathrm{i}}$ (for $\mathrm{i}=\mathrm{I}$, II, III) are time constant parameters, $\mathrm{n}_{\mathrm{i}}$ (for $\mathrm{i}=\mathrm{I}$, II, III) are dimensionless exponents that are related to the slope of the each power-law regime, $\eta_{c}$ is the viscosity of fluid at the critical shear rate, and $\eta_{\max }$ is the viscosity of fluid at $\dot{\Upsilon}_{\max }$ (Figure $3 b$ ). The proposed model is useful for describing both the shear-thinning (either for $\dot{\Upsilon} \leq \dot{\gamma}_{\mathrm{c}}$ or $\dot{\Upsilon}_{\max }<\dot{\gamma}$ ) and shear-thickening $\left(\dot{\gamma}_{\mathrm{c}}<\dot{\gamma} \leq \dot{\Upsilon}_{\max }\right)$ regimes that were observed in the viscosity curve of a shear-thickening fluid [66,67]. However, a drawback of this model is that it possesses a high number of independent constants. 
Shear-thickening behavior in WMS is attributed to shear-induced gelation that formed by long micellar chains [26]. In this approach, gelation occurs when the shear rate is high enough, i.e., above a critical shear rate $\dot{\gamma}_{c}$, to overcome the rotational Brownian diffusion $\left(D_{r}\right)$ of the rod-like micelles [69]:

$$
\dot{\gamma}_{\mathrm{c}} \sim \mathrm{D}_{\mathrm{r}} \sim \frac{\mathrm{k}_{\mathrm{B}} \mathrm{T}}{\pi \mathrm{L}^{3} \eta_{\mathrm{s}}}
$$

where $k_{B}$ is the Boltzmann constant, $T$ is the absolute temperature, $L$ is the length of the rods, and $\eta_{s}$ is the viscosity of the solvent. Barentin and Liu [70] presented a new mechanism for the formation of shear-induced structure, in which the micelles collide under the shear flow and aggregate into bundles. Unlike the approach explaining the shear-induced gelation due to overcoming the Brownian diffusion, they concluded that shear-induced gelation is attributed to micellar-micellar interactions. Section 6.3 presents further discussion on shear-induced structures (SIS).

\subsection{Thermal-Thickening Response}

A major challenge in cEOR is that displacing fluids lose their viscosity at high temperatures of oil reservoirs. One major factor in determining the viscosity of WMS is the contour length (L) of micellar chains [71]. In the mean-field theory of Cates and Candau [72], the average contour length $(\overline{\mathrm{L}})$ is associated with temperature, as follows:

$$
\overline{\mathrm{L}} \sim \phi^{\frac{1}{2}} \exp \left(\frac{\mathrm{E}_{\mathrm{C}}}{2 \mathrm{k}_{\mathrm{B}} \mathrm{T}}\right)
$$

where $\phi$ is the volume fraction of surfactants and Ec is the excess free energy that is associated with hemispherical end caps of micelles as compared to their cylindrical body [72,73]. The decay in contour length with temperature leads to the decrease of viscosity upon increasing the temperature following an Arrhenius law:

$$
\eta_{0} \sim \mathrm{G}_{0} \mathrm{~A} \exp \left(\frac{\mathrm{E}_{\mathrm{a}}}{\mathrm{RT}}\right)
$$

where $E_{a}$ is the flow activation energy, $G_{0}$ is the plateau modulus of WMS, R is the gas constant, and $A$ is the pre-exponential factor [74]. Even though decreasing viscosity with temperature is a common characteristic of WMS, some of WMS have been reported to show a thermal-thickening response where the viscosity increases with temperature. In the following, we focus on studies that reported the WMS with the thermal-thickening behavior that can be beneficial for displacing fluids under the elevated temperature of an oil reservoir.

Sharma et al. [75] studied mixed nonionic WMS whileusing long polyoxyethylene chain phytosterol $\left(\mathrm{Ph}_{\mathrm{y}} \mathrm{EO}_{30}\right)$ and polyoxyethylene dodecyl ether $\left(\mathrm{C}_{12} \mathrm{EO}_{\mathrm{n}}, \mathrm{n}=3\right.$ and 4$)$ surfactants in aqueous solutions. They reported the variation of $\eta_{0}$ as a function of temperature for $5 \mathrm{wt} \%$ of $\mathrm{Ph}_{\mathrm{y}} \mathrm{EO}_{30}+\mathrm{C}_{12} \mathrm{EO}_{3}$ system at $\mathrm{X}=0.36$ - the weight fraction of $\mathrm{C}_{12} \mathrm{EO}_{3}$ in total surfactant. As presented in Figure 4, increasing the temperature from $15{ }^{\circ} \mathrm{C}$ to $30^{\circ} \mathrm{C}$ led to the increase of $\eta_{0}$. Temperature affects the micellar growth and in turn, the viscosity of WMS. These nonionic WMS, including polyoxyethylene head groups, are significantly influenced by temperature because the hydration of oxyethylene is sensitive to temperature. In wormlike micellar structures, the free energy density at the end-caps of wormlike micelles is higher than that of its cylindrical body. The micelles grow in length by reducing the number of end-caps in order to minimize the excess energy at the end-caps. Increasing the temperature enhances the dehydration of the EO-chain of lipophilic cosurfactant, $\mathrm{C}_{12} \mathrm{EO}_{3}$, and decreases the average cross-sectional area of the surfactant. These changes increase the end-cap energy and result in enhanced one-dimensional micellar growth. 


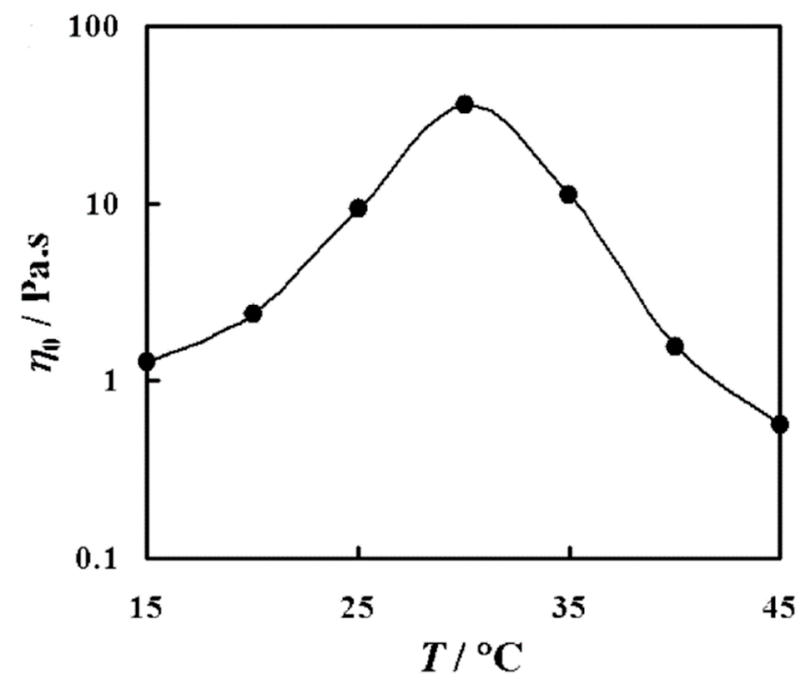

Figure 4. Variation of zero-shear viscosity $\left(\eta_{0}\right)$ as a function of temperature $(T)$ for $5 \mathrm{wt} \% \mathrm{Ph}_{\mathrm{y}} \mathrm{EO}_{30}$ $+\mathrm{C}_{12} \mathrm{EO}_{3} \mathrm{WMS}$ at $\mathrm{X}=0.36$. Reprinted from reference [75] with permission from the American Chemical Society.

Varade et al. [76] reported the thermal-thickening effect of nonionic WMS that was prepared by $\mathrm{C}_{14} \mathrm{EO}_{3}$ and Tween 80 in aqueous media. Figure 5 a shows the typical variation of steady-state viscosity as a function of shear rate for the water/Tween-80/ $\mathrm{C}_{14} \mathrm{EO}_{3}$ system at the weight fraction of $\mathrm{C}_{14} \mathrm{EO}_{3}$ in total amphiphiles, $\mathrm{X}=0.17$ at different temperatures $\left(20,25\right.$, and $\left.30{ }^{\circ} \mathrm{C}\right)$. Increasing the temperature from $20^{\circ} \mathrm{C}$ to $30^{\circ} \mathrm{C}$ results in an increased viscosity of the Newtonian plateau. In addition, the shear-thinning behavior begins at lower shear rates when the temperature is elevated, which means that more micellar structures are formed at higher temperatures. Figure $5 \mathrm{~b}$ represents the zero-shear viscosity of the water/Tween-80/ $\mathrm{C}_{14} \mathrm{EO}_{3}$ solution as a function of $\mathrm{X}$ at different temperatures. Increasing the temperature shifts the viscosity curve to the left, which means that a lower $X$ is required to obtain a comparable viscosity for higher temperatures. The thermal-thickening response is a result of dehydration of polyoxyethylene chains at elevated temperatures. The cross-sectional area at the hydrophile-lipophile interface and, in turn, the curvature of the cylindrical body of micelles decrease upon dehydration of the polyoxyethylene chains. Thus, the increasing length of micelles is more favorable than the formation of end-caps. Micellar growth as a function of temperature results in higher viscosity and a thermal-thickening response.

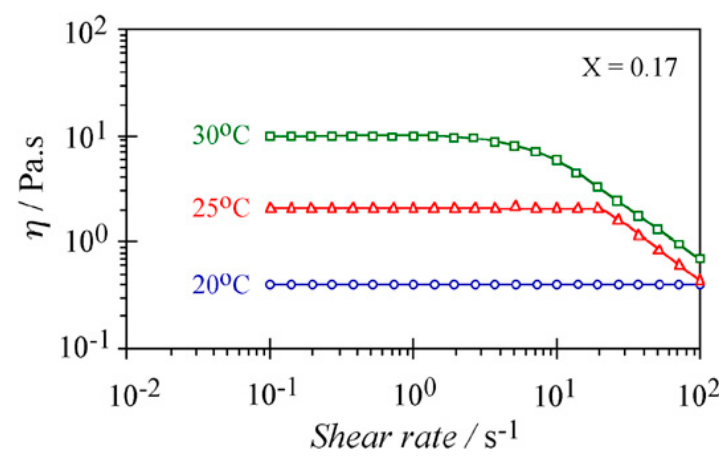

(a)

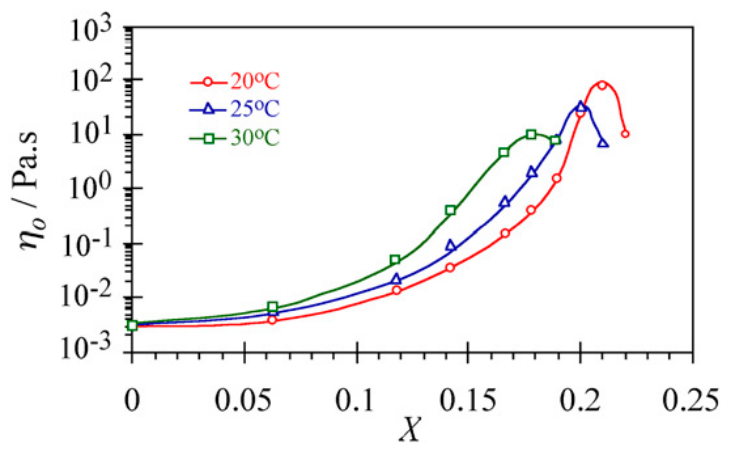

(b)

Figure 5. (a) Steady shear rate of the water/Tween-80/C ${ }_{14} \mathrm{EO}_{3}$ WMS at $\mathrm{X}=0.17$ at different temperatures. (b) Variation of zero-shear viscosity as a function of $X$ at different temperatures in water/Tween-80/ $\mathrm{C}_{14} \mathrm{EO}_{3}$ WMS. The concentration of Tween-80 in water is fixed at $15 \mathrm{wt} \%$. Reprinted from reference [76] with permission from Elsevier. 
The important feature of Sharma [75] and Varade [76] studies is that, even by a slight increase in temperature $\left(15{ }^{\circ} \mathrm{C}\right.$ and $10{ }^{\circ} \mathrm{C}$, respectively), the zero-shear viscosity is enhanced by an order of magnitude, which is in contrast with typical thermal-thinning behavior of viscoelastic solutions described by Equation (10) (see Figure 2) [59,77]. However, in the case of polyoxyethylene solutions, the dehydration of polyoxyethylene leads to a thermal-thickening response.

$\mathrm{Chu}$ and Feng [78] reported the thermo-switchable behavior of WMS, in which the solution shows a reversible transition in its viscosity in response to a thermal stimuli. They used a synthesized sulfobetaine amphiphile, 3-(N-palmitamido propyl-N, N-dimethyl ammonium) propane sulfonate (PDAS) as a zwitterionic surfactant. The viscosity of 1.0 M PDAS micellar solution in the presence of $0.5 \mathrm{M} \mathrm{NaCl}$ is shown in Figure 6 as a function of shear rate. The shear viscosity of the solution at $30{ }^{\circ} \mathrm{C}$ endures a constant shear rate that matches conventional Newtonian fluid behavior. The micellar structures in the lower viscous PDAS/ $\mathrm{NaCl}$ solution at $30^{\circ} \mathrm{C}$ are associated with short rod-like micelles. However, by increasing the temperature to $40{ }^{\circ} \mathrm{C}$, the measured viscosity of the solution is higher than the constant viscosity at a lower temperature through the entire range of shear rates. It also should be noted that the solution displays a non-Newtonian fluid behavior-shear-thinning-which is well acknowledged as evidence of the alignment of wormlike micelles in the direction of the flow field. The viscosity of this solution could be turned on and off by changing the temperature (see Figure 7).

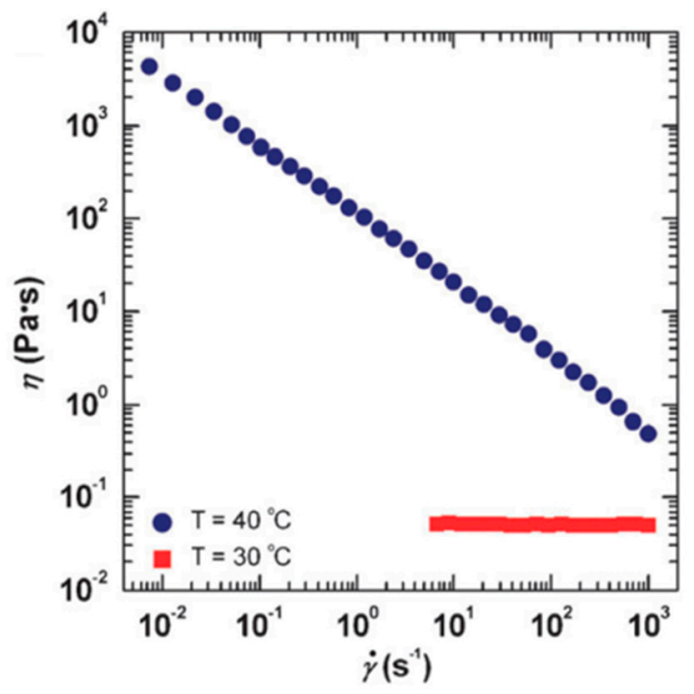

Figure 6. The thermal-thickening behavior of propane sulfonate (PDAS)/ $\mathrm{NaCl}$ WMS. Reprinted from reference [78] with permission from the Royal Society of Chemistry.

The response of PDAS/ $\mathrm{NaCl}$ solution to thermal stimulus is attributed to the decreased solubility of the hydrophobic parts that are influenced by heating. This behavior is similar to what occurs within polymer gels in terms of their weakening gelation upon heating $[59,60]$.

A salting-out effect is a term that explains the decreased solubility of nonelectrolytes in water caused by the addition of electrolytes. Increasing the temperature to $40{ }^{\circ} \mathrm{C}$ leads to an enhanced salting-out effect, thus the solubility of the hydrophobic moieties of PDAS tails decreases. This results in micellization and the growth of the micelles from short rods into entangled long wormlike micelles (see Figure 8). These micellar structures immobilize the water and form hydrogels. In contrast, decreasing the temperature to $30^{\circ} \mathrm{C}$ dissipates entangled long wormlike micelles due to the transfer of amphiphiles from the micellar phase to the bulk. The long self-assembled micelles revert to the short rods and the overall viscosity of the solution significantly decreases [78]. 


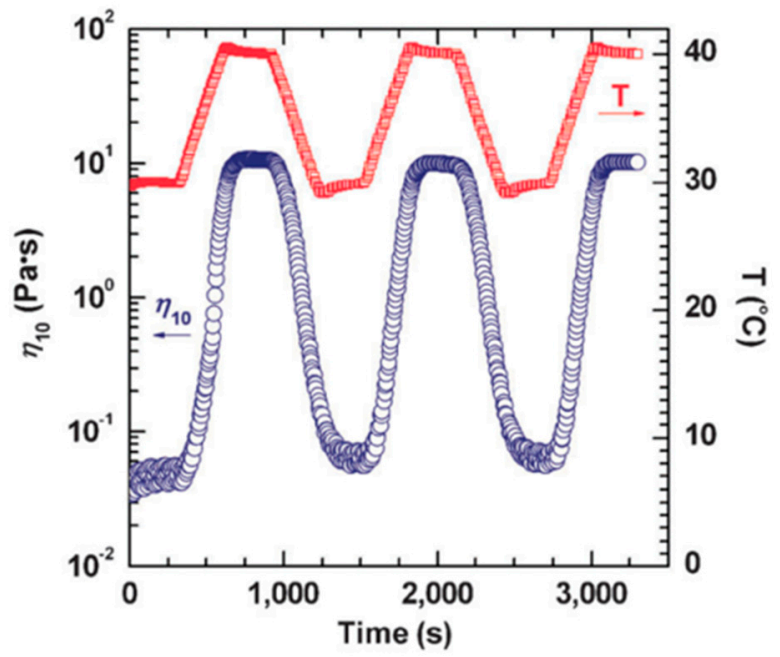

Figure 7. The thermo-reversible rheological response of PDAS/ $\mathrm{NaCl}$ WMS at shear rate of $10 \mathrm{~s}^{-1}$. Reprinted from reference [78] with permission from the Royal Society of Chemistry.

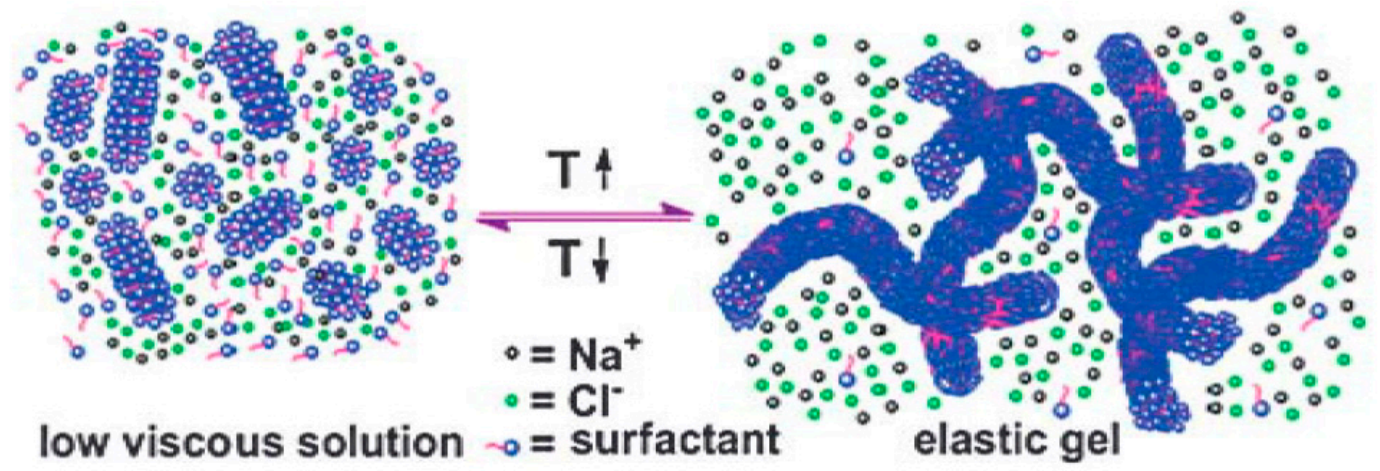

Figure 8. A schematic illustration of the switchable gelation mechanism. Reprinted from reference [78] with permission from the Royal Society of Chemistry.

\subsection{Formation of Shear-Induced Structure (SIS)}

In WMS systems, micellar chains continuously break and reform due to their weak physical bonds (see Section 6.5 for more details). This results in a broad and dynamic distribution of micellar chain lengths that change along with a shear or an extensional flow regime. The resulting flow behavior is even more complex when compared to that of polymeric fluids. Above a critical shear rate in the steady-state shear flow, the shear viscosity increases as a new and more viscous phase develops. This shear-induced state is called shear-induced phase (SIP) [79] or shear-induced structure (SIS) [80]. Rehage and Hoffmann [81,82] observed that an aqueous WMS of $\mathrm{CPyCl} / \mathrm{NaSal}$ forms a gel-like structure along the direction of shear flow above a critical shear rate. This gel-like structure is referred to as an SIS, a structure that will disintegrate with the cessation of the shear flow $[82,83]$. The general rheological response of the $\mathrm{CPyCl} / \mathrm{NaSal}$ solution under the Couette flow condition confirms that the formation and disbanding of SIS increases and decreases the viscosity of the solution, respectively. The formation of SIS occurs when a flow regime causes a stretching and tumbling of wormlike micelles, which invoke micelle-micelle collisions that produce a complex viscous network. Rojas et al. [83] revealed that, while it is not possible for short micelles to form long-range connections under static conditions, these connections can be elongated by imposing an appropriate level of shear stress and, in turn, increase the viscosity. Jones [84] hypothesized that it is possible to employ shear-thickening characteristics to overcome the challenge of preferential flow, which tends to only flow through the high-permeability zones of reservoirs rather than the low-permeability zones, where 
trapped oils remain upswept. This hypothesis also led the work of Golombok et al. [20,85], who carried out experimental investigations on pressure-driven flows within cylindrical glass core samples with different permeability classes. The shear-thickening response that is caused by an associated flow through the high-permeability zones will result in a higher local fluid viscosity when compared to the viscosity of fluid flowing through the low-permeability zones under the same pressure drop. The fluid viscosity decreases in the low-permeability zone as the shear rate decreases. Different frictional losses will be developed according to the variation of the viscosity in different permeability zones. The formation of SIS in WMS is advantageous for the selective retardation of flow in the most permeable zone of reservoirs. SIS form in higher permeability zones because of higher shear rates and increase the fluid viscosity in those regions. Thus, the fluid velocity at higher permeability zones slows down relative to the fluid in the low-permeability zones. Golombok et al. [20] reported that the formation of SIS led to a $36 \%$ increase in the volume of oil that can be swept by WMS displacing fluid when compared to the brine displacing fluid made of $3 \mathrm{wt} \%$ of $\mathrm{NaCl}$ in demineralized water.

\subsection{Salinity Resistance}

Conventional polymer solutions that are used for EOR are not able to sustain their viscosity under high-temperature or high-salinity conditions of oil reservoirs. Viscosity loss and precipitation of most water-soluble polymers can occur due to the presence of divalent cations (i.e., $\mathrm{Ca}^{2+}, \mathrm{Mg}^{2+}$ ), which lead to the hydrolysis of polymers [86]. Polymer solutions, in particular HPAM, are widely used as oil-displacing agents [27]; however, their poor salt tolerance and thermal instability impeded their applications in high-salinity and high-temperature oil reservoirs. More salt-tolerant and thermostable monomer or groups, such as $\mathrm{SO}_{3}{ }^{-}$, onto the HPAM backbone have been introduced to enhance the characteristics of HPAM in a high-salinity and high-temperature environment [87]. However, the main portion of the polymer backbone is still the acrylamide segment, which demonstrates poor long-term thermal stability and salt tolerance. Zhu et al. [12] introduced a complex of wormlike micellar EDAB and HPAM to overcome the deficiencies. The HPAM/EDAB hybrid samples were studied in comparison with sole HPAM and EDAB in a synthetic brine regarding their rheological behaviors. They performed experiments under simulated high-temperature and high-salinity oil reservoir conditions $\left(\mathrm{T}: 85^{\circ} \mathrm{C}\right.$; total dissolved solids, TDS: $\left.32,868 \mathrm{mg} / \mathrm{L} ;\left[\mathrm{Ca}^{2+}\right]+\left[\mathrm{Mg}^{2+}\right]: 873 \mathrm{mg} / \mathrm{L}\right)$. A major factor for the use of any displacing fluid in high-temperature and high-salinity reservoirs is that they enable a solution to retain a high viscosity after exposure to harsh environments. Figure 9 shows the viscosity variations of sole HPAM, EDAB, and two hybrid solutions of them at $85^{\circ} \mathrm{C}$.

While the HPAM solution shows a significant decay in the viscosity as a function of time, the hybrid solutions sustain their viscosity much more effectively than HPAM solution after aging. Most importantly, the EDAB solutions containing the ultra-long-chain zwitterionic surfactant possess long-term stability when compared to other solutions containing HPAM. Even with its long-term stability, the oil recovery factor when using EDAB has been reported to be lower than that when using EDAB/HPAM hybrid solutions. The recovery factor for EDAB was only $1.9 \%$ as compared to the factors of $10.20 \%$ and $7.10 \%$ for P15E15 and P10E20, respectively. The authors suggested that the collapse of micellar assemblies upon contacting with the oil and disassembly of micelles at shear and elongation forces imposed to WMS at pore throats might describe the lower oil recovery factor of EDAB. However, further studies are required for verification of their hypothesis. 


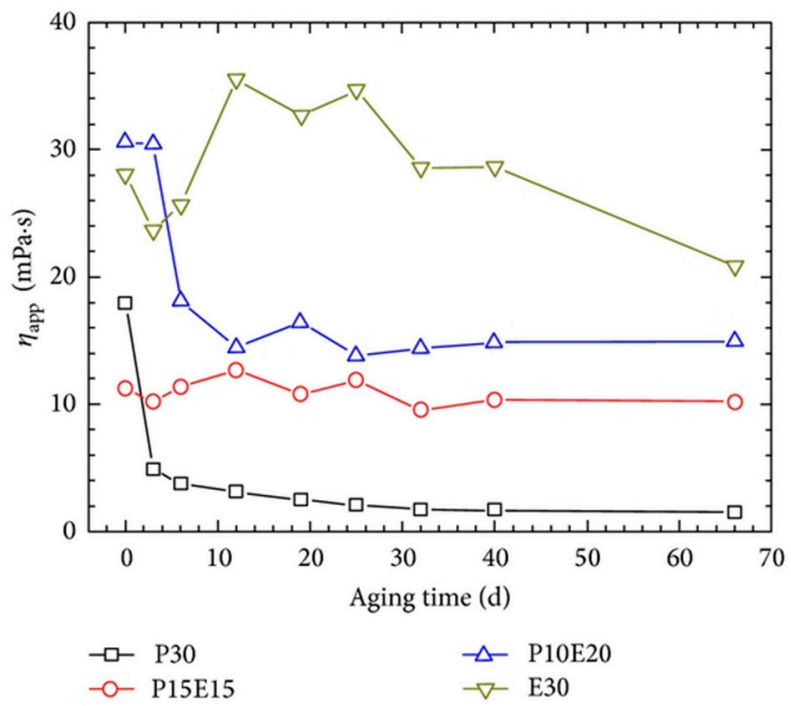

Figure 9. Long-term thermal stability of HPAM/EDAB hybrid samples in comparison with EDAB and HPAM $\left(\right.$ TDS $\left.=32,868 \mathrm{mg} / \mathrm{L},\left[\mathrm{Ca}^{2+}\right]+\left[\mathrm{Mg}^{2+}\right]=873 \mathrm{mg} / \mathrm{L}, \dot{\gamma}=7.34 \mathrm{~s}^{-1}\right)$. Both the aging and measuring temperature is $85{ }^{\circ} \mathrm{C}$. P30: $0.3 \mathrm{wt} \%$ of HPAM and $0 \mathrm{wt} \%$ of EDAB; P10E20: $0.1 \mathrm{wt} \%$ of HPAM and $0.2 \mathrm{wt} \%$ of EDAB; P15E15: $0.15 \mathrm{wt} \%$ of HPAM and 0.15 wt \% of EDAB; and E30: $0 \mathrm{wt} \%$ of HPAM and $0.3 \mathrm{wt} \%$ of EDAB. Reprinted from reference [12] under a Creative Commons license.

Cao et al. [88] studied the effects of adding $\mathrm{NaCl}, \mathrm{Na}_{2} \mathrm{CO}_{3}$ and $\mathrm{NaCl} / \mathrm{NaOH}$ in $\mathrm{NaOA}$ solutions and demonstrated that the zero-shear viscosity of the solution increased with the micellar growth when the concentrations of $\mathrm{Na}_{2} \mathrm{CO}_{3}$ and $\mathrm{NaCl}$ increase (see Figure 10). The reason behind the increased zero-shear viscosity is that, by increasing salt concentrations (electrolytes), the oleic acid salting-out effect leads to longer micellar chains. As shown in Figure 10, both salts induce a significant enhancement of the viscosity. The increase in the length of rod-like micellar chains as a result of the salting-out effect promotes micelles long enough to be wormlike micelles and shows a rapid increase in the zero-shear viscosity.

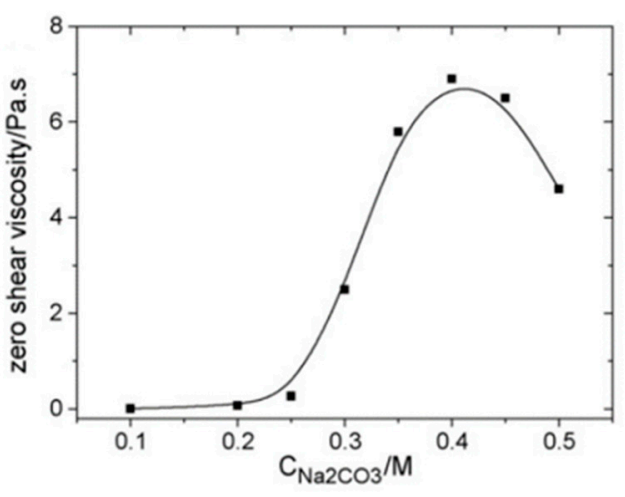

(a)

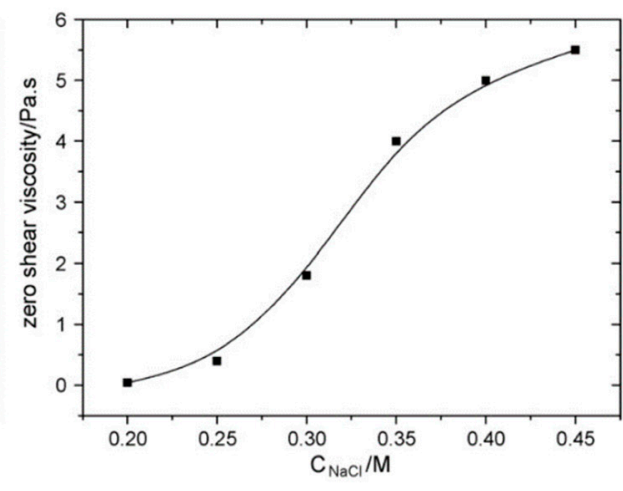

(b)

Figure 10. Zero-shear viscosity of $\mathrm{NaOA} / \mathrm{Na}_{2} \mathrm{CO}_{3} \mathrm{WMS}$ as a function of (a) $\mathrm{Na}_{2} \mathrm{CO}_{3}$ with a fixed $\mathrm{NaOA}$ concentration of $0.060 \mathrm{M}$ and (b) $\mathrm{NaCl}$ concentrations at fixed $\mathrm{NaOA}$ and $\mathrm{NaOH}$ concentrations of $0.60 \mathrm{M}$ and $0.10 \mathrm{M}$, respectively. Reprinted from reference [88] with permission from Elsevier.

However, an excessive concentration of $\mathrm{Na}_{2} \mathrm{CO}_{3}$ (higher than $\sim 0.4 \mathrm{M}$ ) results in a decrease in the zero-shear viscosity. The reason is that excessive electrolyte might further reduce the net charge of the micelles and the linear micellar chains may turn into branched micellar chains. Unlike branching in polymers, it has been reported that branching in micelles assists stress relaxation, which results in a 
shortened relaxation time and lower zero-shear viscosity. The branched points of wormlike micelles are not chemical connections and the wormlike micelles can slide against one another (i.e., reptation). Reptation can occur along every path of branched wormlike micelles as a mechanism for the stress relaxation, which leads to very low zero-viscosity $[89,90]$. The difference in the viscosity trend at high salt concentrations between $\mathrm{NaCl}$ and $\mathrm{Na}_{2} \mathrm{CO}_{3}$ is because of hydroxide ions that can suppress the hydrolysis of oleic acid. The hydration of $\mathrm{CO}_{3}{ }^{2-}$ is not as prominent as that of $\mathrm{Cl}^{-}$; therefore, less wormlike micellar chains of oleic acid are subjected to hydrolysis in the presence of $\mathrm{Cl}^{-}$than $\mathrm{CO}_{3}{ }^{2-}$ ions. These studies are evidence that ultra-long chain zwitterionic surfactants, such as EBDA and anionic-based WMS solutions, are promising materials that can enhance the tolerance of displacing fluids against the high-salinity conditions of oil reservoirs.

\subsection{Reversible Scission}

Even though wormlike micelles show many of the same viscoelastic characteristics of polymers, they are quite physically different from polymers. One of the significant behavioral differences between WMS and polymer solutions stems from the type of bonds in their structures. In polymer solutions, monomers are covalently bonded to each other to form a chain. In this way, once they are formed, the polymer chains are not easily dissociated. In wormlike micelles, surfactants units aggregate together by relatively weak physical attractions. The micellar structures in the equilibrium state break and reform continuously, where the kinetics of breakage and reformation reactions are greatly dependent on the surfactants and salt concentrations, temperature, and flow. The dynamic break and reform of WMS is the reason that they are also called living polymers [59]. Branched wormlike micelles relax from imposed stresses via reptation. According to the living polymer model [91], wormlike micelles can relax from stresses while using an additional mechanism in which the micellar chains breakdown into shorter micellar chains. In wormlike micelles, the micellar breaking time $\left(\tau_{b}\right)$ is shorter than reptation time $\left(\tau_{r}\right)$, thus the breaking of the micellar structure is the dominant mechanism for stress relaxation time $\left(\tau_{R}\right)$. The stress relaxation time of micelles is the geometric mean $\left(\tau_{R} \sim \sqrt{\tau_{r} \tau_{b}}\right)$ of breaking and reptation times.

To date, various approaches have been taken to model the behavior of WMS by considering their breakage and reformation dynamics. Marques et al. [92] suggested that wormlike micelles can relieve stress by eliminating the entanglement points through a bond interchange mechanism. In this mechanism, two micellar chains that have an entanglement can react and form a transient four-arm star shape of micelles and then break into two new chains of different lengths. Appell et al. [93] suggested ghostlike crossing as another possible mechanism for stress relaxation of wormlike micelles. When a micellar chain collides with another chain, it forms a transient crosslink on the side where it collides, and then separates from the other side of the micellar chain. However, as the authors stated, a theoretical description of such behavior requires further investigation.

Bautista et al. [94] proposed a kinetic equation for WMS by taking the shear rate effect on the breaking and reformation into account. In this model, the breakage rate of micellar chains is considered as a function of the local shear rate. The model describes the appearance of stress plateau in a WMS flow curve at higher shear rates than the first critical shear rate. The model also predicts that WMS with higher micellar breakage rates have stress plateau values at a lower critical shear rate. Vasquez et al. [95] suggested a network scission model in which a micellar chain with the length L can break in the middle to develop two micelles of length $\mathrm{L} / 2$. The micellar breakage occurs at a rate that depends on the shear rate and the local elongation rate. The shorter micelles can then recombine to reform a micellar chain back to the initial length.

Several oilfield treatment processes impose different shear stresses on a fluid over the course of its employment. For example, in hydraulic fracturing, a fluid may experience very high shear as it flows through wellbore tubular and perforation orifices, but then subsequently must suspend and transport particles for an extended time (possibly hours) at low shear rates [96]. In the case of using polymeric displacing fluids, these sudden changes in shear rates are not desired, because the 
viscosity of displacing fluid permanently decreases under the shear rate due to the shear-thinning characteristics of polymer solutions. Thus, the ability of wormlike micellar structures to reform after shear exposure is a fundamental advantage over polymer solutions. Wormlike micelles can display a temporary shear-thinning behavior under injection conditions and then reform their assembly and gain their initial viscosity in the reservoir [97].

\subsection{Drag Reduction}

High-molecular-weight polymers, including flexible chains, are widely used as drag-reducing agents. They are more effective at lower concentrations, such as a few ppm. However, these materials drop their effectiveness permanently under the extreme shear or extensional stresses due to the breakage of primary bonds, predominantly near the chains' midpoints [98]. A number of studies investigated the influence of wormlike micellar structure and their rheological characteristics on drag reduction [99-101]. The authors reported that there is a correlation between drag reduction and high apparent extensional viscosity. High extensional viscosity enables WMS and polymer solutions to resist against vortex stretching, which results in lower energy dissipation, or so-called drag reduction phenomena [102]. An analysis of drag reduction that is caused by polymer-induced turbulence revealed that there is a maximum drag reduction asymptote (MDRA), which is the maximum extent of drag reduction that can be achieved [103]. Although there are similar mechanisms of drag reduction suggested for polymer and wormlike micelles, MDRAs of WMS drag reducing agents (DRA) have been reported to be $5 \%$ to $15 \%$ higher than that of polymer DRA, depending on Reynolds number [104]. Brostow [105], Wang et al. [106], and Hong et al. [107] provided findings regarding the drag reduction in transportation of viscoelastic solutions. Despite the fact that the mechanism of drag reduction is still considered puzzling, it has been agreed that injection of macromolecules such as polymer chains and wormlike micelles leads to the reduction of turbulence in a sublayer adjacent to the solid pipe wall and it reduces the friction between the fluid and walls [108]. Drag reduction can be calculated, as

$$
\operatorname{DR}(\%)=\left(\frac{\mathrm{f}_{\mathrm{S}}-\mathrm{f}_{\mathrm{DRA}}}{\mathrm{f}_{\mathrm{S}}}\right) \times 100=\left(1-\frac{\Delta \mathrm{P}_{\mathrm{DRA}} \cdot \mathrm{Q}_{\mathrm{s}}{ }^{2}}{\Delta \mathrm{P}_{\mathrm{S}} \cdot \mathrm{Q}_{\mathrm{DRA}}{ }^{2}}\right) \times 100
$$

where $\mathrm{f}$ is the friction factor, $\Delta \mathrm{P}$ is the pressure drop, $\mathrm{Q}$ is the volumetric flow rate, and indices of $\mathrm{S}$ and DRA refer to the solvent and drag reducing agents, respectively [108]. Kotenko et al. [109] studied the drug reduction while using two WMS prepared by dissolving commercial surfactant-based DRA (Beraid DR-IW 616 and 618, AkzoNobel, Amsterdam, The Netherlands) and sodium nitrite in deionized water. The authors measured the pressure drop in test rigs with main components of a centrifugal pump, a water tank, expansion tanks, and straight sections of pipes, and reported the drug reduction of $60 \%$ to $80 \%$ when using WMS as compared to pure water. The drag reduction is attributed to the presence of wormlike micellar chains that serve as a buffer between the neighboring turbulent eddies, and consequently reduce turbulence of the flow. Moreover, authors suggested that wormlike micelles form a viscous sublayer adjacent to the wall of the pipes, which reduces the friction between the test fluid and pipe walls (Figure 11a).

In many applications, VES are effective DRA, as well as particle suspension media. The major application of drag reduction is to enhance the flow rate in crude oil pipelines by the addition of polymers and surfactants [110]. When comparing the MDRA of surfactant fluids to that of polymer solutions reveals the superior drag reduction of the surfactant under the same flow conditions [111,112]. Additionally, surfactant DRA have significant advantages, such as the ability to restructure their micellar assemblies and sustained rheological properties, even after being exposed to high shear (Figure 11b). This shear-recovery attribute is a notable advantage over polymer solutions that can be irreversibly degraded during fluid pumping $[5,109,113]$. 
a)

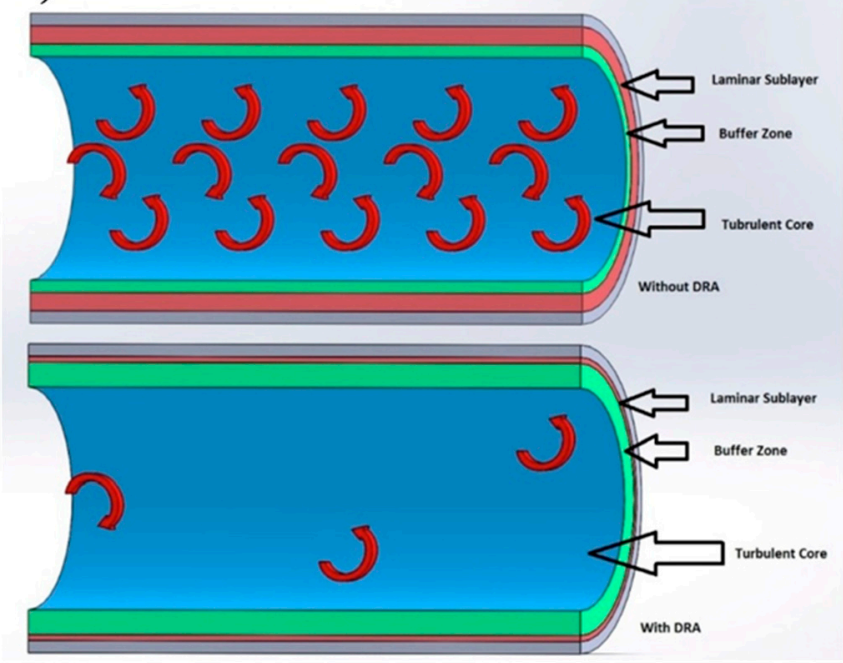

b)

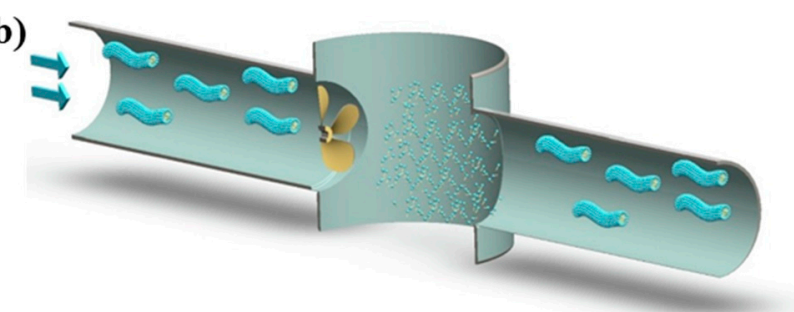

Figure 11. (a) The dampening mechanism of the turbulent bursts. (b) Rearrangement of broken wormlike micelles after crossing a pump. Reprinted from reference [109] with the permission from Elsevier.

\subsection{Hydrocarbon Responsivity}

The addition of hydrocarbons significantly influences the behavior of WMS systems. Entangled wormlike micellar networks can be eliminated by adding a small quantity of hydrocarbons, and thus the initial viscoelastic WMS is transformed into a Newtonian water-like solution. Surfactant micellar solutions tend to dissolve a certain amount of hydrocarbons by the interaction between the hydrocarbon and the hydrophobic core of micelles. Even though aqueous solutions containing globular micelles are able to trap a small amount of hydrocarbons, the maximum concentration of dispersed hydrocarbons in these solutions is lower by at least one order of magnitude than the concentration of the surfactants. However, solutions containing wormlike micelles dissolve larger amounts of hydrocarbons in which the hydrocarbon/surfactant ratio can reach about one, as reported by Hoffmann and Ebert [81]. Hydrocarbons induce the transformation of entangled wormlike micellar chains into isolated globular aggregates with radii from 20 to $500 \AA$. Thus, the viscoelastic WMS can be turned into a Newtonian low-viscosity solution.

Shibaev et al. [114] investigated the effect of hydrocarbon addition on the rheological characteristics and the structure of WMS formed by potassium oleate. In their study, the addition of $0.5 \mathrm{wt} \% \mathrm{n}$-dodecane results in a drastic decrease in viscosity by up to five orders of magnitude. This is attributed to the complete disruption of wormlike micellar chains and the formation of micro-emulsion droplets. As demonstrated in Figure 12, the transition state of wormlike micellar chains to micro-emulsion droplets can be classified into three regions:

- In region I, the WMS demonstrates high values of viscosity $(\sim 10-350 \mathrm{~Pa} \cdot \mathrm{s})$, because the micellar chains are still entangled with each other. However, their lengths are reduced by the dissolved hydrocarbons. 
- In region II, the micellar chains are transformed to the unentangled regime and the viscosity drastically drops due to a further shortening of micellar chains and the formation of micro-emulsion droplets.

- In region III, the viscosity is as low as $\sim 0.001 \mathrm{~Pa} \cdot \mathrm{s}$, in which only microemulsion droplets are present in the solution.

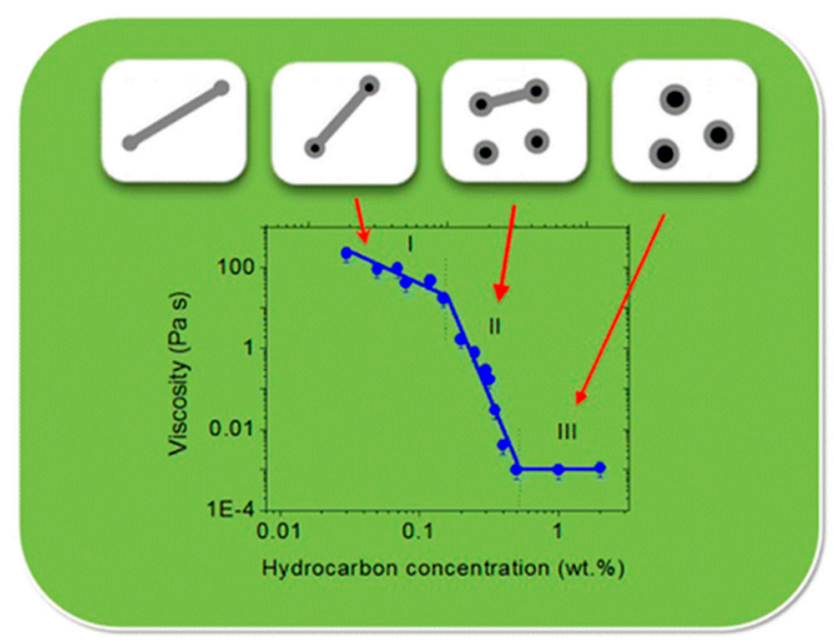

Figure 12. The dependency of zero-shear viscosity on the hydrocarbon (n-dodecane) concentration in 3 $\mathrm{wt} \%$ potassium oleate solution. Reprinted from reference [114] with permission from the American Chemical Society.

The authors suggested that the shortening mechanism of micellar chains that are involved with the preferential accumulation of the solubilized hydrocarbon at the end-caps of wormlike micellar chains. In the formation of wormlike micelles, the higher energy at the end-caps of micelles when compared to the body leads to the lengthening of micelles and formation of long cylindrical micelles. The drastic decrease in the viscosity is correlated with the crossover from the entangled to the unentangled regimes of the WMS upon the shortening of micelles and the shortened cylindrical micelles coexist along with microemulsion droplets in region II.

In another study, Shibaev et al. [115] investigated the responsiveness of linear and branched anionic/cationic-mixed wormlike surfactant micelles to hydrocarbon. They prepared linear and branched micelles by changing the molar ratios of potassium oleate and n-octyltrimethylammonium bromide $\left(\mathrm{C}_{8} \mathrm{TAB}\right)$ dissolved in salt-free water. Linear wormlike micelles with the molar ratio of $\left[\mathrm{C}_{8} \mathrm{TAB}\right] /[$ potassium oleate $]=0.5$ show a dramatic drop of viscosity upon the addition of small amounts of n-decane as reported in their previous study [114] (Figure 12). However, in the other case of molar ratio of 1, wormlike micelles are branched, and much higher concentration of $\mathrm{n}$-decane is required for the significant drop of viscosity. The authors suggested that the solubilization of hydrocarbon was proceeded in branching points, not in the end-caps. Thus, micellar chains are prevented from shortening and the rheological properties of WMS are not significantly affected up to the saturation of branching points by the hydrocarbon solubilization [115]. In this way, one can conclude that the rheological stability of branched micellar chains is more resilient to hydrocarbon solubilization when compared to that of linear chains.

Fogang et al. [116] studied the effect of different organic compounds solubilization on the zero-shear viscosity of an aqueous solution of a sulfobetaine viscoelastic surfactant. They prepared the solution by dissolving $3.96 \mathrm{wt} \%$ of erucamidopropyl hydroxypropyl sulfobetaine and $6.2 \mathrm{wt} \%$ of calcium chloride $\left(\mathrm{CaCl}_{2}\right)$ in deionized water and investigated the effects of $\mathrm{n}$-decane, crude oil (CO), and extra virgin olive oil (EVOO) on the zero-shear viscosity of WMS. The solubilization of n-decane resulted in three regimes of viscosity change similar to that reported in ref. [114]. However, both EVOO and CO in WMS 
only resulted in the regime I at $30^{\circ} \mathrm{C}$ and regimes of I and II at $60^{\circ} \mathrm{C}$. Authors concluded that higher molecular components of $\mathrm{CO}$ and EVOO as compared to that of n-decane resulted in less solubilization in WMS. They also concluded that the viscosity reduction of WMS was dependent on the balance between micellization and oil solubilization.

The interaction between WMS and hydrocarbons can be beneficial for sweeping oil in low-permeability zones. While highly viscous displacing fluids sweep the oil in high-permeability zones, low-permeability zones with high saturated hydrocarbons are retained. Therefore, the interaction between hydrocarbons and WMS in low-permeability zones decreases the viscosity and enhances the permeability of displacing fluids into those areas [90].

\section{Conclusions and Outlook}

WMS are promising materials for cEOR that combine the advantage of both displacing fluid viscosifiers and lowering IFT of surfactants. The wide application of cEOR methods is restricted due to the degraded functionality of displacing fluids that are influenced by the high-salinity and high-temperature environment of oil reservoirs. The unique characteristics of WMS make them powerful candidates for overcoming cEOR restrictions. One of the major restrictions in using the polymer flooding method is that there is a high probability for the polymer chains to block the low-permeability zones of oil reservoirs. The shear-thinning property of WMS and breakage of wormlike micelles under high shear stress conditions lead to a better injectivity and provide the ability to sweep the trapped oil in low-permeability zones. Permanent degradation is another risk when using polymer solutions in cEOR. The reversible scission of wormlike micelles makes them tolerant against permanent shear degradation. Polymer-based solutions are highly sensitive to the presence of ions in oil reservoir environments. Surfactant- and alkaline-based solutions are also susceptible to a reaction with ions and absorption to the rock structures. Complex solutions of alkaline-surfactant-polymers are shown to have low stability in high-salinity conditions because of the risk of chromatographic separation. In contrast to all of them, ultra-long chain zwitterionic surfactants and anionic surfactant-based WMS display sustained high viscosity and aging stability against harsh conditions. A major challenge of EOR arises from the heterogeneous structures of oil reservoirs that are made up of higher and lower permeability zones in which displacing fluids tend to pass through high-permeability zones and leave the low-permeability zones unswept. The formation of SIS in WMS increases the viscosity and retards the flow in the high-permeability zones relative to the less permeable areas. Thus, WMS displacing fluids divert more flow to the less permeable zones and increase the oil recovery. In addition to these common useful characteristics of WMS, the living characteristic of wormlike micelles provides a broad research field of investigations to find or design smart wormlike structures. The thermal-thickening of WMS based on the salting-out effect is an example of using the living nature of micelles to change their rheological response.

Although WMS, such as EBDA, show a higher tolerance of high-salinity conditions when compared to polymer solutions, their oil recovery factors are still limited. The collapse of micelles due to the hydrocarbon-micellar interaction is suggested as the main reason for the lower recovery factor of EBDA. On the other hand, hybrid displacing fluids of polymer/WMS show higher recovery factors. Investigations on the hydrocarbon-responsive characteristics of WMS point out that the hydrocarbon-WMS interaction is advantageous for diverting the displacing fluid into the less permeable and unswept zones. When considering the heterogeneous structures of oil reservoirs, further studies must be conducted on designing hybrid displacing fluids or multi-step recovery processes that sweep the oil in all reservoir areas. Injecting a shear-thinning displacing fluid for sweeping high-permeability zones and the subsequent injection of WMS hydrocarbon-responsive fluid for sweeping oil in unswept zones is an example of the desired multi-step recovery processes. 
Author Contributions: Conceptualization, E.J.N. and N.K.; Investigation and Analysis, E.J.N. and N.K.; Writing-Original Draft, E.J.N.; Writing—Review and Editing, E.J.N., T.Y., Y.J.L. and N.K.; Funding Acquisition, Y.J.L and N.K.

Funding: This research was funded by American Chemical Society Petroleum Research Fund (ACS-PRF 57552-ND9).

Acknowledgments: The authors would like to acknowledge the financial support from the Office of Provost \& Vice President for Academic Affairs and the REP program at Texas State University as well as the Donors of the American Chemical Society Petroleum Research Fund.

Conflicts of Interest: The authors declare no conflict of interest.

\section{References}

1. Kokal, S.; Al-Kaabi, A. Enhanced Oil Recovery: Challenges E Opportunities; World Petroleum Council: London, UK, 2010.

2. Al-Mjeni, R.; Arora, S.; Cherukupalli, P.; van Wunnik, J.; Edwards, J.; Felber, B.J.; Gurpinar, O.; Hirasaki, G.J.; Miller, C.A.; Jackson, C. Has the Time Come for EOR? Oilfield Rev. 2010, $2011,4$.

3. Thomas, S. Enhanced oil recovery-An overview. Oil Gas Sci. Technol.-Rev. D'IFP Energ. Nouv. 2008, 63, 9-19. [CrossRef]

4. Terry, R.E. Enhanced oil recovery. Encycl. Phys. Sci. Technol. 2001, 18, 503-518.

5. Muggeridge, A.; Cockin, A.; Webb, K.; Frampton, H.; Collins, I.; Moulds, T.; Salino, P. Recovery rates, enhanced oil recovery and technological limits. Phil. Trans. R. Soc. A 2014, 372, 20120320. [CrossRef] [PubMed]

6. Delshad, M.; Kim, D.H.; Magbagbeola, O.A.; Huh, C.; Pope, G.A.; Tarahhom, F. Mechanistic interpretation and utilization of viscoelastic behavior of polymer solutions for improved polymer-flood efficiency. In Proceedings of the SPE Symposium on Improved Oil Recovery, Tulsa, OK, USA, 20-23 April 2008; Society of Petroleum Engineers: Richardson, TX, USA.

7. Sorbie, K.S. Polymer-Improved Oil Recovery; Springer Science \& Business Media: Berlin, Germany, 2013.

8. Morvan, M.; Degre, G.; Beaumont, J.; Colin, A.; Dupuis, G.; Zaitoun, A.; Al-maamari, R.S.; Al-Hashmi, A.A.R.; Al-Sharji, H.H. Viscosifying surfactant technology for heavy oil reservoirs. In Proceedings of the SPE Heavy Oil Conference Canada, Calgary, AB, Canada, 12-14 June 2012; Society of Petroleum Engineers: Richardson, TX, USA.

9. Mayer, E.H.; Berg, R.L.; Carmichael, J.D.; Weinbrandt, R.M. Alkaline injection for enhanced oil recovery-A status report. J. Pet. Technol. 1983, 35, 209-221. [CrossRef]

10. Lake, L.W.; Venuto, P.B. A niche for enhanced oil recovery in the 1990s. Oil Gas J. 1990, 88, 62-67.

11. Austad, T.; Shariatpanahi, S.; Strand, S.; Black, C.; Webb, K. Conditions for a low-salinity enhanced oil recovery (EOR) effect in carbonate oil reservoirs. Energy Fuels 2011, 26, 569-575. [CrossRef]

12. Zhu, D.; Zhang, J.; Han, Y.; Wang, H.; Feng, Y. Laboratory study on the potential EOR use of HPAM/VES hybrid in high-temperature and high-salinity oil reservoirs. J. Chem. 2013, 2013, 1-8. [CrossRef]

13. Han, M.; AlSofi, A.; Fuseni, A.; Zhou, X.; Hassan, S. Development of chemical EOR formulations for a high temperature and high salinity carbonate reservoir. In Proceedings of the IPTC 2013: International Petroleum Technology Conference, Beijing, China, 26-28 March 2013.

14. Zhang, Z.; Li, J.; Zhou, J. Microscopic roles of "viscoelasticity" in HPMA polymer flooding for EOR. Transp. Porous Media 2011, 86, 199-214. [CrossRef]

15. Wei, B.; Romero-Zerón, L.; Rodrigue, D. Oil displacement mechanisms of viscoelastic polymers in enhanced oil recovery (EOR): A review. J. Pet. Explor. Prod. Technol. 2014, 4, 113-121. [CrossRef]

16. Nasr-El-Din, H.; Hawkins, B.; Green, K. Viscosity behavior of alkaline, surfactant, polyacrylamide solutions used for enhanced oil recovery. In Proceedings of the SPE International Symposium on Oilfield Chemistry, Anaheim, CA, USA, 20-22 February 1991.

17. Ghannam, M.; Esmail, N. Flow behavior of enhanced oil recovery alcoflood polymers. J. Appl. Polym. Sci. 2002, 85, 2896-2904. [CrossRef]

18. Savins, J. Non-Newtonian flow through porous media. Ind. Eng. Chem. 1969, 61, 18-47. [CrossRef]

19. Lee, K.S. Performance of a polymer flood with shear-thinning fluid in heterogeneous layered systems with crossflow. Energies 2011, 4, 1112-1128. [CrossRef] 
20. Golombok, M.; van der Wijst, R. Permeability thickening fluids for improved secondary oil recovery. J. Pet. Sci. Eng. 2013, 110, 22-26. [CrossRef]

21. Lakatos, I.J.; Toth, J.; Bodi, T.; Lakatos-Szabo, J.; Berger, P.D.; Lee, C.H. Application of viscoelastic surfactants as mobility-control agents in low-tension surfactant floods. In Proceedings of the International Symposium on Oilfield Chemistry, Houston, TX, USA, 28 February-2 March 2007.

22. Kjøniksen, A.-L.; Beheshti, N.; Kotlar, H.K.; Zhu, K.; Nyström, B. Modified polysaccharides for use in enhanced oil recovery applications. Eur. Polym. J. 2008, 44, 959-967. [CrossRef]

23. Taylor, K.C.; Nasr-El-Din, H.A. Water-soluble hydrophobically associating polymers for improved oil recovery: A literature review. J. Pet. Sci. Eng. 1998, 19, 265-280. [CrossRef]

24. Berret, J.-F.; Gamez-Corrales, R.; Oberdisse, J.; Walker, L.; Lindner, P. Flow-structure relationship of shear-thickening surfactant solutions. EPL (Europhys. Lett.) 1998, 41, 677. [CrossRef]

25. Gamez-Corrales, R.; Berret, J.-F.; Walker, L.; Oberdisse, J. Shear-thickening dilute surfactant solutions: Equilibrium structure as studied by small-angle neutron scattering. Langmuir 1999, 15, 6755-6763. [CrossRef]

26. Bruinsma, R.; Gelbart, W.M.; Ben-Shaul, A. Flow-induced gelation of living (micellar) polymers. J. Chem. Phys. 1992, 96, 7710-7727. [CrossRef]

27. Jung, J.C.; Zhang, K.; Chon, B.H.; Choi, H.J. Rheology and polymer flooding characteristics of partially hydrolyzed polyacrylamide for enhanced heavy oil recovery. J. Appl. Polym. Sci. 2013, 127, 4833-4839. [CrossRef]

28. Jang, H.Y.; Zhang, K.; Chon, B.H.; Choi, H.J. Enhanced oil recovery performance and viscosity characteristics of polysaccharide xanthan gum solution. J. Ind. Eng. Chem. 2015, 21, 741-745. [CrossRef]

29. Luo, J.-H.; Pu, R.-Y.; Wang, P.-M.; Bai, F.-L.; Zhang, Y.; Yang, J.-B.; Liu, Y.-Z. Performance Properties of Salt Tolerant Polymer KYPAM for EOR. Oilfield Chem. 2002, 19, 64-67.

30. Ju, S.; Zhonghua, W.; Ning, H.; Xudong, L. Synthesis and performance evaluation of AMPS/AM tercopolymer for eor. Chem. Eng. Oil Gas 2001, 4, 013.

31. Sheng, J.J. Chapter 5-Polymer Flooding. In Modern Chemical Enhanced Oil Recovery; Gulf Professional Publishing: Boston, MA, USA, 2011; pp. 101-206. [CrossRef]

32. Seright, R.S.; Campbell, A.; Mozley, P.; Han, P. Stability of Partially Hydrolyzed Polyacrylamides at Elevated Temperatures in the Absence of Divalent Cations. In Proceedings of the SPE International Symposium on Oilfield Chemistry, The Woodlands, TX, USA, 20-22 April 2009. [CrossRef]

33. Levitt, D.; Pope, G.A. Selection and Screening of Polymers for Enhanced-Oil Recovery. In Proceedings of the SPE Symposium on Improved Oil Recovery, Tulsa, OK, USA, 20-23 April 2008.

34. Algharaib, M.; Alajmi, A.; Gharbi, R. Investigation of Polymer Flood Performance in High Salinity Oil Reservoirs. In Proceedings of the SPE/DGS Saudi Arabia Section Technical Symposium and Exhibition, Al-Khobar, Saudi Arabia, 15-18 May 2011.

35. Puerto, M.; Miller, C.A.; Hirasaki, G.J.; Barnes, J.R. Surfactant systems for EOR in high-temperature, high-salinity environments. In Proceedings of the SPE Improved Oil Recovery Symposium, Tulsa, OK, USA, 24-28 April 2010.

36. Ibrahim, Z.B.; Manap, A.A.A.; Hamid, P.A.; Hon, V.Y.; Lim, P.H.; Wyatt, K. Laboratory Aspect of Chemical EOR Processes Evaluation for Malaysian Oilfields. In Proceedings of the SPE Asia Pacific Oil \& Gas Conference and Exhibition, Adelaide, Australia, 11-13 September 2006.

37. Pope, G.A. Recent developments and remaining challenges of enhanced oil recovery. J. Pet. Technol. 2011, 63, 65-68. [CrossRef]

38. Qiuzhi, Z.T.W.Z.G.; Xingqi, H. Synthesis and Evaluation of Anionic AM/AMPS Copolymer. Adv. Fine Petrochem. 2006, 12, 006.

39. Al-Sofi, A.M.; La Force, T.; Blunt, M.J. Sweep impairment due to polymers shear thinning. In Proceedings of the SPE Middle East Oil and Gas Show and Conference, Manama, Bahrain, 15-18 March 2009.

40. Silva, J.A.K.; Smith, M.M.; Munakata-Marr, J.; McCray, J.E. The effect of system variables on in situ sweep-efficiency improvements via viscosity modification. J. Contam. Hydrol. 2012, 136, 117-130. [CrossRef] [PubMed]

41. Lee, W.; Makarychev-mikhailov, S.M.; Lastre Buelvas, M.J.; Abad, C.; Christiawan, A.B.; Narayan, S.; Singh, M.M.; Sengupta, S. Fast Hydrating Fracturing Fluid for Ultrahigh Temperature Reservoirs. In Proceedings of the Abu Dhabi International Petroleum Exhibition and Conference, Abu Dhabi, UAE, 10-13 November 2014. 
42. Lei, C.; Clark, P.E. Crosslinking of guar and guar derivatives. In Proceedings of the SPE Annual Technical Conference and Exhibition, Houston, TX, USA, 26-29 September 2004.

43. Abad, C.; Mirakyan, A.L.; Parris, M.D.; Chen, Y.; Mueller, F.A. Rheological Characterization of Novel Delayed-Transition Metal Crosslinked Fracturing Fluids: Correlation with First Field Applications. In Proceedings of the SPE Annual Technical Conference and Exhibition, New Orleans, LA, USA, 4-7 October 2009.

44. Siggel, L.; Santa, M.; Hansch, M.; Nowak, M.; Ranft, M.; Weiss, H.; Hajnal, D.; Schreiner, E.; Oetter, G.; Tinsley, J. A new class of viscoelastic surfactants for enhanced oil recovery. In Proceedings of the SPE Improved Oil Recovery Symposium, Tulsa, OK, USA, 14-18 April 2012.

45. Somasundaran, P.; Hanna, H. Adsorption of sulfonates on reservoir rocks. Soc. Pet. Eng. J. 1979, 19, $221-232$. [CrossRef]

46. Mohan, K. Alkaline surfactant flooding for tight carbonate reservoirs. In Proceedings of the SPE Annual Technical Conference and Exhibition, New Orleans, LA, USA, 4-7 October 2009; Society of Petroleum Engineers: Richardson, TX, USA, 2009.

47. Li, N.; Zhang, G.; Ge, J.; Luchao, J.; Jianqiang, Z.; Baodong, D.; Pei, H. Adsorption behavior of betaine-type surfactant on quartz sand. Energy Fuels 2011, 25, 4430-4437. [CrossRef]

48. Olajire, A.A. Review of ASP EOR (alkaline surfactant polymer enhanced oil recovery) technology in the petroleum industry: Prospects and challenges. Energy 2014, 77, 963-982. [CrossRef]

49. Hou, J.; Liu, Z.; Zhang, S.; Yang, J. The role of viscoelasticity of alkali/surfactant/polymer solutions in enhanced oil recovery. J. Pet. Sci. Eng. 2005, 47, 219-235. [CrossRef]

50. Li, D.; Shi, M.-Y.; Wang, D.; Li, Z. Chromatographic separation of chemicals in alkaline surfactant polymer flooding in reservoir rocks in the Daqing oil field. In Proceedings of the SPE International Symposium on Oilfield Chemistry, The Woodlands, TX, USA, 20-22 April 2009.

51. Dreiss, C.A. Wormlike micelles: Where do we stand? Recent developments, linear rheology and scattering techniques. Soft Matter 2007, 3, 956-970. [CrossRef]

52. Kamal, M.S. A review of gemini surfactants: Potential application in enhanced oil recovery. J. Surfactants Deterg. 2016, 19, 223-236. [CrossRef]

53. Ezrahi, S.; Tuval, E.; Aserin, A. Properties, main applications and perspectives of worm micelles. Adv. Colloid Interface Sci. 2006, 128, 77-102. [CrossRef] [PubMed]

54. Morvan, M.; Moreau, P.; Degre, G.; Leng, J.; Masselon, C.; Bouillot, J.; Zaitoun, A. New Viscoelastic Fluid for Chemical EOR. In Proceedings of the SPE International Symposium on Oilfield Chemistry, The Woodlands, TX, USA, 20-22 April 2009.

55. Fjelde, I.; Austad, T.; Milter, J. Adsorption VII. Dynamic adsorption of a dual surfactant system onto reservoir cores at seawater salinities. J. Pet. Sci. Eng. 1995, 13, 193-201. [CrossRef]

56. Graf, K.; Kappl, M. Physics and Chemistry of Interfaces; John Wiley \& Sons: Hoboken, NJ, USA, 2006.

57. González-Pérez, A.; Ruso, J.M.; Prieto, G.; Sarmiento, F. Temperature-Sensitive Critical Micelle Transition of Sodium Octanoate. Langmuir 2004, 20, 2512-2514. [CrossRef] [PubMed]

58. Acharya, D.P.; Varade, D.; Aramaki, K. Effect of temperature on the rheology of wormlike micelles in a mixed surfactant system. J. Colloid Interface Sci. 2007, 315, 330-336. [CrossRef] [PubMed]

59. Wang, J.; Feng, Y.; Agrawal, N.R.; Raghavan, S.R. Wormlike micelles versus water-soluble polymers as rheology-modifiers: Similarities and differences. Phys. Chem. Chem. Phys. 2017, 19, 24458-24466. [CrossRef]

60. Sharma, M.M.; Yen, T.; Chilingarian, G.; Donaldson, E. Some Chemical and Physical Problems in Enhanced Oil Recovery Opzrations. Dev. Pet. Sci. 1985, 17, 223-249.

61. Liu, C.-H.; Pine, D. Shear-induced gelation and fracture in micellar solutions. Phys. Rev. Lett. 1996, 77, 2121. [CrossRef]

62. Hu, Y.; Wang, S.; Jamieson, A. Rheological and flow birefringence studies of a shear-thickening complex fluid-A surfactant model system. J. Rheol. 1993, 37, 531-546. [CrossRef]

63. Hu, Y.; Rajaram, C.; Wang, S.; Jamieson, A. Shear thickening behavior of a rheopectic micellar solution: Salt effects. Langmuir 1994, 10, 80-85. [CrossRef]

64. Hu, Y.; Matthys, E.F. Characterization of micellar structure dynamics for a drag-reducing surfactant solution under shear: Normal stress studies and flow geometry effects. Rheol. Acta 1995, 34, 450-460. [CrossRef]

65. Gabbanelli, S.; Drazer, G.; Koplik, J. Lattice Boltzmann method for non-Newtonian (power-law) fluids. Phys. Rev. E 2005, 72, 046312. [CrossRef] 
66. Galindo-Rosales, F.; Rubio-Hernández, F.; Sevilla, A.; Ewoldt, R.H. How Dr. Malcom, M. Cross may have tackled the development of "An apparent viscosity function for shear thickening fluids". J. Non-Newton. Fluid Mech. 2011, 166, 1421-1424. [CrossRef]

67. Galindo-Rosales, F.; Rubio-Hernández, F.; Sevilla, A. An apparent viscosity function for shear thickening fluids. J. Non-Newton. Fluid Mech. 2011, 166, 321-325. [CrossRef]

68. Cross, M.M. Rheology of non-Newtonian fluids: A new flow equation for pseudoplastic systems. J. Colloid Sci. 1965, 20, 417-437. [CrossRef]

69. Doi, M.; Edwards, S.F. The Theory of Polymer Dynamics; Oxford University Press: Oxford, UK, 1988; Volume 73.

70. Barentin, C.; Liu, A. Shear thickening in dilute solutions of wormlike micelles. EPL (Europhys. Lett.) 2001, 55, 432. [CrossRef]

71. Vogtt, K.; Jiang, H.; Beaucage, G.; Weaver, M. Free Energy of Scission for Sodium Laureth-1-Sulfate Wormlike Micelles. Langmuir 2017, 33, 1872-1880. [CrossRef]

72. Cates, M.; Candau, S. Statics and dynamics of worm-like surfactant micelles. J. Phys. Condens. Matter 1990, 2, 6869. [CrossRef]

73. Tung, S.-H.; Huang, Y.-E.; Raghavan, S.R. Contrasting effects of temperature on the rheology of normal and reverse wormlike micelles. Langmuir 2007, 23, 372-376. [CrossRef]

74. Raghavan, S.R.; Kaler, E.W. Highly Viscoelastic Wormlike Micellar Solutions Formed by Cationic Surfactants with Long Unsaturated Tails. Langmuir 2001, 17, 300-306. [CrossRef]

75. Sharma, S.C.; Shrestha, L.K.; Tsuchiya, K.; Sakai, K.; Sakai, H.; Abe, M. Viscoelastic wormlike micelles of long polyoxyethylene chain phytosterol with lipophilic nonionic surfactant in aqueous solution. J. Phys. Chem. B 2009, 113, 3043-3050. [CrossRef]

76. Varade, D.; Ushiyama, K.; Shrestha, L.K.; Aramaki, K. Wormlike micelles in Tween-80/CmEO3 mixed nonionic surfactant systems in aqueous media. J. Colloid Interface Sci. 2007, 312, 489-497. [CrossRef]

77. Croce, V.; Cosgrove, T.; Maitland, G.; Hughes, T.; Karlsson, G. Rheology, cryogenic transmission electron spectroscopy, and small-angle neutron scattering of highly viscoelastic wormlike micellar solutions. Langmuir 2003, 19, 8536-8541. [CrossRef]

78. Chu, Z.; Feng, Y. Thermo-switchable surfactant gel. Chem. Commun. 2011, 47, 7191-7193. [CrossRef]

79. Lindner, P.; Bewersdorff, H.; Heen, R.; Sittart, P.; Thiel, H.; Langowski, J.; Oberthür, R. Drag-reducing surfactant solutions in laminar and turbulent flow investigated by small-angle neutron scattering and light scattering. In Trends in Colloid and Interface Science IV; Springer: Berlin/Heidelberg, Germany, 1990; pp. 107-112.

80. Boltenhagen, P.; Hu, Y.; Matthys, E.; Pine, D. Observation of bulk phase separation and coexistence in a sheared micellar solution. Phys. Rev. Lett. 1997, 79, 2359. [CrossRef]

81. Hoffmann, H.; Ebert, G. Surfactants, micelles and fascinating phenomena. Angew. Chem. Int. Ed. 1988, 27, 902-912. [CrossRef]

82. Rehage, H.; Hoffmann, H. Rheological properties of viscoelastic surfactant systems. J. Phys. Chem. 1988, 92, 4712-4719. [CrossRef]

83. Rojas, M.R.; Müller, A.J.; Sáez, A.E. Shear rheology and porous media flow of wormlike micelle solutions formed by mixtures of surfactants of opposite charge. J. Colloid Interface Sci. 2008, 326, 221-226. [CrossRef]

84. Jones, W. Polymer additives in reservoir flooding for oil recovery: Shear thinning or shear thickening? J. Phys. D Appl. Phys. 1980, 13, L87. [CrossRef]

85. Reuvers, N.; Golombok, M. Shear rate and permeability in water flooding. Transp. Porous Media 2009, 79, 249-253. [CrossRef]

86. Vermolen, E.; Van Haasterecht, M.J.; Masalmeh, S.K.; Faber, M.J.; Boersma, D.M.; Gruenenfelder, M.A. Pushing the envelope for polymer flooding towards high-temperature and high-salinity reservoirs with polyacrylamide based ter-polymers. In Proceedings of the SPE Middle East Oil and Gas Show and Conference, Manama, Bahrain, 25-28 September 2011.

87. Dupuis, G.; Rousseau, D.; Tabary, R.; Argillier, J.-F.; Grassl, B. Hydrophobically modified sulfonated polyacrylamides for IOR: Correlations between associative behavior and injectivity in the diluted regime. Oil Gas Sci. Technol.-Rev. D'IFP Energ. Nouv. 2012, 67, 903-919. [CrossRef]

88. Cao, Q.; Yu, L.; Zheng, L.-Q.; Li, G.-Z.; Ding, Y.-H.; Xiao, J.-H. Rheological properties of wormlike micelles in sodium oleate solution induced by sodium ion. Colloids Surf. A Physicochem. Eng. Asp. 2008, 312, 32-38. [CrossRef] 
89. Rogers, S.A.; Calabrese, M.A.; Wagner, N.J. Rheology of branched wormlike micelles. Curr. Opin. Colloid Interface Sci. 2014, 19, 530-535. [CrossRef]

90. Lequeux, F. Reptation of connected wormlike micelles. EPL (Europhys. Lett.) 1992, 19, 675. [CrossRef]

91. Cates, M. Reptation of living polymers: Dynamics of entangled polymers in the presence of reversible chain-scission reactions. Macromolecules 1987, 20, 2289-2296. [CrossRef]

92. Marques, C.M.; Turner, M.S.; Cates, M.E. Relaxation mechanisms in worm-like micelles. J. Non-Cryst. Solids 1994, 172, 1168-1172. [CrossRef]

93. Appell, J.; Porte, G.; Khatory, A.; Kern, F.; Candau, S. Static and dynamic properties of a network of wormlike surfactant micelles (cetylpyridinium chlorate in sodium chlorate brine). J. Phys. II 1992, 2, 1045-1052. [CrossRef]

94. Bautista, F.; Soltero, J.; Pérez-López, J.; Puig, J.; Manero, O. On the shear banding flow of elongated micellar solutions. J. Non-Newton. Fluid Mech. 2000, 94, 57-66. [CrossRef]

95. Vasquez, P.A.; McKinley, G.H.; Cook, L.P. A network scission model for wormlike micellar solutions: I. Model formulation and viscometric flow predictions. J. Non-Newton. Fluid Mech. 2007, 144, 122-139. [CrossRef]

96. Samuel, M.M.; Dismuke, K.I.; Card, R.J.; Brown, J.E.; England, K.W. Methods of Fracturing Subterranean Formations. Google Patents US6306800B1, 23 October 2001.

97. Van Santvoort, J.; Golombok, M. Sweep enhancers for oil recovery. J. Pet. Explor. Prod. Technol. 2016, 6, 473-480. [CrossRef]

98. Zana, R.; Kaler, E.W. Giant Micelles: Properties and Applications; CRC Press: Boca Raton, FA, USA, 2007; Volume 140.

99. Štern, P.; Myška, J. Viscous and elastic properties of a cationic and a zwitterionic drag reducing surfactant. Colloids Surf. A Physicochem. Eng. Asp. 2001, 183, 527-531. [CrossRef]

100. Zakin, J.L.; Lu, B.; Bewersdorff, H.-W. Surfactant drag reduction. Rev. Chem. Eng. 1998, 14, $253-320$. [CrossRef]

101. Lin, Z.; Chou, L.; Lu, B.; Zheng, Y.; Davis, H.T.; Scriven, L.; Talmon, Y.; Zakin, J.L. Experimental studies on drag reduction and rheology of mixed cationic surfactants with different alkyl chain lengths. Rheol. Acta 2000, 39, 354-359. [CrossRef]

102. Lu, B.; Li, X.; Scriven, L.; Davis, H.; Talmon, Y.; Zakin, J. Effect of chemical structure on viscoelasticity and extensional viscosity of drag-reducing cationic surfactant solutions. Langmuir 1998, 14, 8-16. [CrossRef]

103. Virk, P.S. Drag reduction fundamentals. AIChE J. 1975, 21, 625-656. [CrossRef]

104. Zakin, J.L.; Myska, J.; Chara, Z. New limiting drag reduction and velocity profile asymptotes for nonpolymeric additives systems. AIChE J. 1996, 42, 3544-3546. [CrossRef]

105. Brostow, W. Drag reduction in flow: Review of applications, mechanism and prediction. J. Ind. Eng. Chem. 2008, 14, 409-416. [CrossRef]

106. Wang, Y.; Yu, B.; Zakin, J.L.; Shi, H. Review on drag reduction and its heat transfer by additives. Adv. Mech. Eng. 2011, 3, 478749. [CrossRef]

107. Hong, C.; Jang, C.; Choi, H. Turbulent drag reduction with polymers in rotating disk flow. Polymers 2015, 7, 1279-1298. [CrossRef]

108. Nesyn, G.V.; Sunagatullin, R.Z.; Shibaev, V.P.; Malkin, A.Y. Drag reduction in transportation of hydrocarbon liquids: From fundamentals to engineering applications. J. Pet. Sci. Eng. 2018, 161, 715-725. [CrossRef]

109. Kotenko, M.; Oskarsson, H.; Bojesen, C.; Nielsen, M.P. An experimental study of the drag reducing surfactant for district heating and cooling. Energy 2019, 178, 72-78. [CrossRef]

110. Bewersdorff, H.-W.; Ohlendorf, D. The behaviour of drag-reducing cationic surfactant solutions. Colloid Polym. Sci. 1988, 266, 941-953. [CrossRef]

111. Myska, J.; Zakin, J.L. Differences in the flow behaviors of polymeric and cationic surfactant drag-reducing additives. Ind. Eng. Chem. Res. 1997, 36, 5483-5487. [CrossRef]

112. Utracki, L.A.; Jamieson, A.M. Polymer Physics: From Suspensions to Nanocomposites and Beyond; John Wiley \& Sons: Hoboken, NJ, USA, 2011.

113. Elbing, B.R.; Solomon, M.J.; Perlin, M.; Dowling, D.R.; Ceccio, S.L. Flow-induced degradation of drag-reducing polymer solutions within a high-Reynolds-number turbulent boundary layer. J. Fluid Mech. 2011, 670, 337-364. [CrossRef] 
114. Shibaev, A.V.; Tamm, M.V.; Molchanov, V.S.; Rogachev, A.V.; Kuklin, A.I.; Dormidontova, E.E.; Philippova, O.E. How a viscoelastic solution of wormlike micelles transforms into a microemulsion upon absorption of hydrocarbon: New insight. Langmuir 2014, 30, 3705-3714. [CrossRef]

115. Shibaev, A.V.; Kuklin, A.I.; Philippova, O.E. Different responsiveness to hydrocarbons of linear and branched anionic/cationic-mixed wormlike surfactant micelles. Colloid Polym. Sci. 2019, 297, 351-362. [CrossRef]

116. Fogang, L.T.; Sultan, A.S.; Kamal, M.S. Understanding viscosity reduction of a long-tail sulfobetaine viscoelastic surfactant by organic compounds. RSC Adv. 2018, 8, 4455-4463. [CrossRef]

(C) 2019 by the authors. Licensee MDPI, Basel, Switzerland. This article is an open access article distributed under the terms and conditions of the Creative Commons Attribution (CC BY) license (http://creativecommons.org/licenses/by/4.0/). 